\title{
Review Article \\ Cerebrospinal Fluid and Blood Biomarkers of Neuroaxonal Damage in Multiple Sclerosis
}

\author{
Irena Dujmovic \\ Neurology Clinic, Clinical Center of Serbia, Dr Subotica 6, P.O. Box 12, 11129 Belgrade 102, Serbia \\ Correspondence should be addressed to Irena Dujmovic, irdujm@eunet.rs
}

Received 20 December 2010; Accepted 8 February 2011

Academic Editor: Robert Weissert

Copyright () 2011 Irena Dujmovic. This is an open access article distributed under the Creative Commons Attribution License, which permits unrestricted use, distribution, and reproduction in any medium, provided the original work is properly cited.

Following emerging evidence that neurodegenerative processes in multiple sclerosis (MS) are present from its early stages, an intensive scientific interest has been directed to biomarkers of neuro-axonal damage in body fluids of MS patients. Recent research has introduced new candidate biomarkers but also elucidated pathogenetic and clinical relevance of the well-known ones. This paper reviews the existing data on blood and cerebrospinal fluid biomarkers of neuroaxonal damage in MS and highlights their relation to clinical parameters, as well as their potential predictive value to estimate future disease course, disability, and treatment response. Strategies for future research in this field are suggested.

\section{Introduction}

Multiple sclerosis (MS) is a chronic disease of the central nervous system (CNS) characterized by unpredictable clinical relapses and remissions and/or by progression of disability over time [1]. Relapses are considered to be the clinical expression of acute inflammation in the CNS, whereas progression reflects chronic demyelination, gliosis, and axonal loss [2]. Although axonal/neuronal damage has been recognized in MS for more than a century [3], a refocused interest on the role of axonal pathology and neurodegeneration as the cause of permanent neurological disability in MS patients appeared since the 1990s [49]. The development of new immunostaining protocols and new magnetic resonance imaging (MRI) techniques has enabled earlier detection of more subtle changes in diffuse neuroaxonal pathology not only within focal white matter $[6,10]$ and gray matter lesions [11-13], but also within normal appearing white matter (NAWM) [14-16] and normal appearing gray matter in MS $[14,15]$. Current evidence suggests that axonal loss occurs at an early stage of MS $[6,17]$, but because of CNS compensatory mechanisms it remains clinically silent until a threshold level of axonal loss is achieved and the functional reserve capacity is exhausted $[9,18]$. Subsequent progressive axonal loss underlies a continuous and irreversible neurological decline [19], causing a transition from initially relapsing remitting (RR) to the secondary-progressive (SP) MS [7, 9].

Since inflammation correlates only poorly with disability and the loss of neurons and axons may be subject to biochemical monitoring [20], biochemical markers of neuroaxonal degeneration gain increasing importance. Such biomarkers could provide tools for development and evaluation of new therapeutic strategies [21] and might serve as prescreening tools and/or cross-sectional surrogate endpoints in MS clinical trials $[22,23]$, more importantly in those testing potentially axon-protective compounds [24]. Additionally, the assessment of neuroaxonal biomarkers could help in better understanding of MS pathogenesis and identification of disease subtypes [22], as well as in routine patient management for (1) prediction of conversion to MS after a first clinical episode, (2) early prediction of disease course and future disability, (3) selection of patients for individually tailored treatments, and (4) monitoring of disease activity and individual treatment response [23, 2527]. However, it is unlikely that a single biomarker could serve for any of these aims due to the extreme complexity of the pathogenetic processes which cause tissue damage and neuroaxonal loss in MS [26].

Recent research has introduced new candidate biomarkers but also elucidated pathogenetic and clinical relevance 
of the well-known ones. This paper reviews the existing data on blood and cerebrospinal fluid (CSF) biomarkers of neuroaxonal damage in MS in the light of their clinical relevance and suggests strategies for future research in this field.

\section{Mechanisms of Neuroaxonal Damage in MS}

The mechanisms leading to axonal damage in MS are essentially not well elucidated [21]. However, challenging some clinical [28-30], neuroradiological [31], and neuropathological $[11,32]$ observations that neurodegeneration in MS might progress independently from or even precede the inflammation, recent neuropathological reports confirmed the positive correlation between axonal pathology and the degree of inflammation even in cases with progressive MS $[33,34]$. This further supports the scenario in which a variety of effectors from the inflammatory microenvironment could injure axons, such as direct attack by autoreactive antibodies [35-37] or cytotoxic CD8 ${ }^{+}$-cells $[36,38,39]$, invading macrophages, proteolytic enzymes, cytokines, nitric oxide [39-41] and free radicals $[42,43]$, defects in calcium homeostasis [21], glutamate-mediated excitotoxicity [43, 44], an increased axonal energy demand [45], and mitochondrial injury and failure $[45,46]$ (Figure 1). Axonal damage could also be secondary to acute or chronic demyelination $[6,47]$, damaging changes in sodium channel distribution [2, 48], and disruption of axonal/glial interactions $[49,50]$ as well as related to the lack of myelin-derived trophic deprivation and/or impaired axonal regeneration by axon growth inhibitory molecules including those from myelin debris recently called myelin-associated inhibitory factors (MAIFs) such as myelin-associated glycoprotein, oligodendrocyte myelin glycoprotein, Nogo-A, semaphorin 4D/CD100, and ephrin B3 [51, 52] (Figure 1).

\section{Biomarkers of Neuroaxonal Damage in Multiple Sclerosis}

Following damaging processes, molecules released from neuronal cytoplasm, membrane, or nucleus are released into the extracellular CNS compartment (Figure 2) and their further metabolic, transport, and reuptake mechanisms, drainage pathways or other interactions with the CNS tissue, as well as the degree of tissue destruction would determine the level of these substances in CSF and blood [21].

CSF analysis is more pathology specific as it provides information from the body fluid that is most closely associated to the disease process [53], but sometimes substances measured in lumbar-sac-CSF are not necessarily completely representative of brain pathology [20]. However, there is a need for new biomarkers in more easily accessible body fluids such as peripheral blood [53], since substances produced within the CNS and found in the blood could also be representative of the ongoing CNS pathology [20].

CSF and/or blood levels of biomarkers associated with neuroaxonal injury in patients with MS and clinically isolated syndrome suggestive of MS (CIS) are summarized in

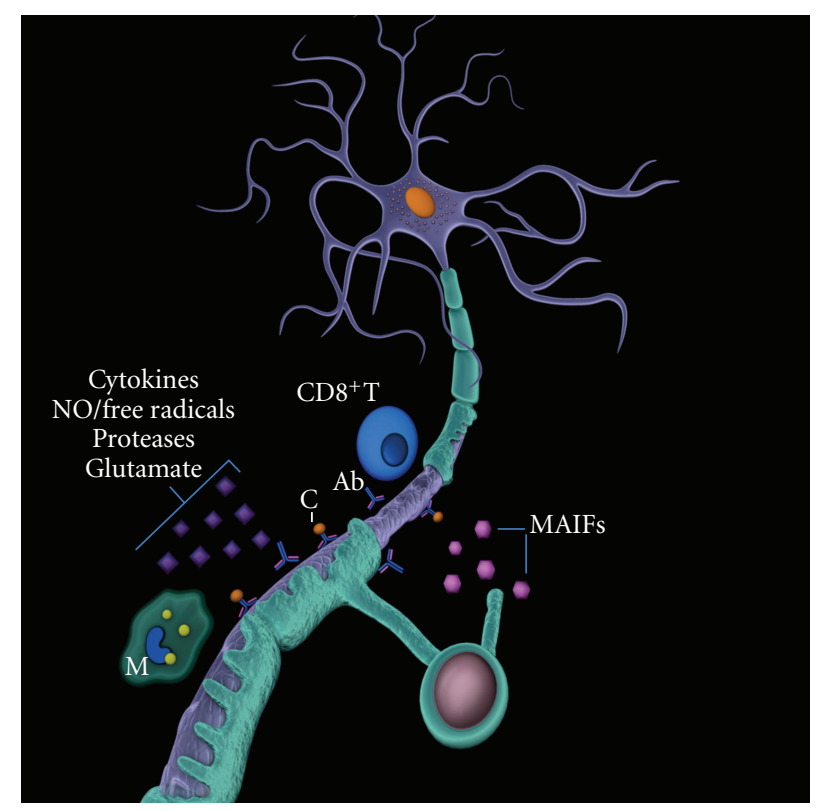

FIGURE 1: The mechanisms of neuroaxonal damage in multiple sclerosis. Legend: NO: nitric oxide; M: macrophage; C: complement; Ab: antibody; $\mathrm{CD}^{+} \mathrm{T}$ : $\mathrm{CD}^{+} \mathrm{T}-$ lymphocyte; MAIFs: myelinassociated inhibitory factors.

Tables 1, 3, 4 and 5 and their relation to clinical parameters in Table 2.

3.1. Neurofilaments. Neurofilaments (NFs) are cytoskeletal proteins which play a role in stabilizing axons, determining axon diameter and participate in axonal transport [54, 55]. As NFs are found exclusively within neurons, their detection in blood or CSF therefore reflects neuronal and axonal damage [56]. Mammalian NFs consist of different subunits: NF-light chain (NF-L), which serves as a backbone for NFintermediate chain (NF-M) and a heavy chain (NF-H) to copolymerise [21]. The most abundant, the smallest and most soluble NF subunit is NF-L but is susceptible to proteases [57]. On the other hand, HF-H is a larger molecule and more resistant to proteases if phosphorylated [58]. Phosphorylated parts of NF molecules are mostly abundant within HF-M and NF-H subunits [59], and the state of phosphorylation influences axonal diameter [60]. The highly phosphorylated NF-H are normally found only in axonal NFs and this marker is thought to indicate axonal injury and/or degeneration [56], whereas NF-L constitutes only a minor part of the neuronal cell body and dendrites relative to axons [61]. NF-H phosphorylation may increase during the progressive phase of MS [62]. Due to the lower molecular weight of NF-L and/or its lower phosphorylation rate, NF-L could diffuse earlier from the parenchyma into CSF than NF-H, but also could be degraded quicker [54]. Although changes in the blood-brain barrier (BBB) might influence the CSF NF-L concentration, the degree of such influence was considered to be negligible [61]. 
TABLE 1: Neurofilament subunits in the cerebrospinal fluid (CSF) and blood of patients with multiple sclerosis (MS) and/or clinically isolated syndrome suggestive of MS (CIS).

\begin{tabular}{|c|c|c|c|c|c|}
\hline $\begin{array}{l}\text { Biomarker } \\
\text { (subtype) }\end{array}$ & Body fluid & Immunoassay & Number of patients & Main findings & REF \\
\hline \multirow{8}{*}{ NF-L (cytoplasmic) } & CSF & ELISA & $60 \mathrm{MS}(\mathrm{RR})$ & $\mathrm{RR} \uparrow \uparrow \mathrm{HCo}$ & {$[61]$} \\
\hline & CSF & Dot-blot & $35 \mathrm{MS}(\mathrm{RR} / \mathrm{SP} / \mathrm{PP})$ & $\mathrm{MS} \uparrow \uparrow \mathrm{OIND}$ or NIND, PP/SP $\uparrow \uparrow \mathrm{RR}$ & [63] \\
\hline & CSF & ELISA & $66 \mathrm{MS}(\mathrm{RR} / \mathrm{SP})$ & $\mathrm{RR} / \mathrm{SP} \uparrow \uparrow \mathrm{HCo}$ & [64] \\
\hline & CSF & ELISA & 99 MS (RR/SP/PP/PR) & $\mathrm{RR} / \mathrm{SP} / \mathrm{PP} \uparrow \uparrow \mathrm{NHCo}$, SP the highest & [65] \\
\hline & CSF & ELISA & $51 \mathrm{MS}(\mathrm{RR} / \mathrm{SP} / \mathrm{PP})$ & not detected & [66] \\
\hline & CSF & ELISA & $47 \mathrm{MS}$ & MS $\uparrow \uparrow$ healthy siblings or HCo & [67] \\
\hline & CSF & ELISA & $76 \mathrm{MS}(\mathrm{RR} / \mathrm{SP} / \mathrm{PP})+38 \mathrm{CIS}$ & CIS+MS $\uparrow \uparrow \mathrm{NIND}+\mathrm{OIND}+\mathrm{NHCo}$ & [54] \\
\hline & CSF & ELISA & $5 \mathrm{MS}(\mathrm{RR})$ & $\mathrm{MS} \uparrow \uparrow \mathrm{NHCo}$ & [68] \\
\hline NF-M (cytoplasmic) & $\mathrm{CSF} / \mathrm{PL} / \mathrm{SE}$ & $\begin{array}{c}\text { not } \\
\text { investigated }\end{array}$ & - & - & - \\
\hline \multirow{9}{*}{ NF-H (cytoplasmic) } & CSF & ELISA & $38 \mathrm{MS}(\mathrm{RR})+52$ CIS & NF-H ${ }^{\text {SMI35 }}$ in CIS $\uparrow \uparrow \mathrm{NHCo}$ & {$[25]$} \\
\hline & CSF & ELISA & $41 \mathrm{ON}$ & $\begin{array}{l}\mathrm{NF}-\mathrm{H}^{\mathrm{SMI} 34} \text { and } \mathrm{NF}-\mathrm{H}^{\mathrm{SMI} 34 / \mathrm{SMI} 35} \text { in } \mathrm{ON} \uparrow \uparrow \\
\text { OND }\end{array}$ & [69] \\
\hline & CSF & ELISA & $51 \mathrm{MS}(\mathrm{RR} / \mathrm{SP} / \mathrm{PP})$ & $\mathrm{NF}-\mathrm{H}^{\mathrm{SMI} 35} \mathrm{RR} \leftrightarrow \mathrm{SP} \leftrightarrow \mathrm{PP}$ & [66] \\
\hline & CSF & ELISA & $34 \mathrm{MS}(\mathrm{RR} / \mathrm{SP} / \mathrm{PP})$ & $\begin{array}{c}\mathrm{NF}^{-\mathrm{H}^{\mathrm{SMI}} 34} \text { in } \mathrm{PP} / \mathrm{SP} \uparrow \uparrow \mathrm{RR}, \mathrm{NF}-\mathrm{H}^{\mathrm{SMI} 35} \text { in } \\
\mathrm{SP} / \mathrm{PP} \uparrow \uparrow \mathrm{RR}\end{array}$ & {$[62]$} \\
\hline & CSF & ECL & $95 \mathrm{MS}$ & $\mathrm{MS} \uparrow \uparrow \mathrm{NHCo}$ & [23] \\
\hline & CSF & ELISA & $24 \mathrm{MS}(\mathrm{RR} / \mathrm{SP} / \mathrm{PP})$ & $\mathrm{NF}-\mathrm{H}^{\mathrm{SMI} 35}$ in $\mathrm{SP} \uparrow \mathrm{RR}$ & [70] \\
\hline & PL & ELISA & $18 \mathrm{ON}$ & $\mathrm{NF}-\mathrm{H}^{\mathrm{SMI} 35}$ in $\mathrm{ON} \uparrow \uparrow \mathrm{HCo}$ & [71] \\
\hline & CSF & ELISA & $34 \mathrm{MS}(\mathrm{RR})$ & $\mathrm{NF}-\mathrm{H}^{\mathrm{SMI} 35}$ in $\mathrm{MS} \uparrow \uparrow \mathrm{NHCo}$ & [72] \\
\hline & CSF & ELISA & $76 \mathrm{MS}(\mathrm{RR} / \mathrm{SP} / \mathrm{PP})+38 \mathrm{CIS}$ & $\begin{array}{c}\mathrm{NF}-\mathrm{H}^{\mathrm{SMI} 35} \text { in } \mathrm{MS}+\mathrm{CIS} \uparrow \uparrow \mathrm{NHCo}+\mathrm{NIND} \\
+ \text { OIND }\end{array}$ & [54] \\
\hline
\end{tabular}

REF: reference; NF-L: neurofilament-light chain; NF-M: neurofilament-intermediate chain; NF-H: neurofilament-heavy chain; PL: plasma; SE: serum; ELISA: Enzyme-Linked Immunosorbent Assay; ECL: Electrochemiluminescence-based solid-phase sandwich immunoassay; RR: relapsing-remitting MS; SP: secondary-progressive MS; PP: primary-progressive MS; ON: optic neuritis; NF- $\mathrm{H}^{\mathrm{SMI} 35}$ : NF-H phosphorylated form; NF- ${ }^{\mathrm{SMI} 34}$ : NF-H hyperphosphorylated form; $\uparrow \uparrow$ significantly higher than; $\uparrow$ higher than; $\leftrightarrow$ no difference between; HCo: healthy controls; OIND: other inflammatory neurological diseases; NIND: noninflammatory neurological disorders; NHCo: neurologically healthy controls; OND: other neurological diseases.

Healthy individuals have no NF-L in their CSF, whereas most people with neurological disorders, such as amyotrophic lateral sclerosis, stroke, MS and Alzheimer's disease, can have elevated levels [73]. Several studies have shown the increase of the CSF NF-L levels in MS or CIS patients (Table 1), in the latter more so in those who converted to MS within 3 years [54]. On the other hand, CSF NF-L was detectable at low concentrations [74], or even undetectable in some other studies albeit the assay was similar to that used by others [66]. CSF NF-L levels were reported to be increased during acute relapses [54, 64], in patients with enhancing MRI lesions [54], as well as in patients with higher relapse rate [61] (Table 2) and were also shown to have a peak during the first two months after the start of the previous exacerbation and to gradually decrease thereafter to a low level [61]. A correlation between NF-L with Expanded Disability Status Scale (EDSS) score as a disability measure was found in some studies [54, 63]. Norgren et al. [65] reported a significant correlation between CSF NF-L levels and progression index over 10 years whereas in a recent study the risk for high Multiple Sclerosis Severity Score (MSSS) at long-term follow-up after 14 years was increased threefold for cases with high NF-L levels [75]. Conversion from RRMS to SPMS was more likely in cases with high CSF
NF-L levels when compared with those with undetectable or intermediate NF-L levels [75] (Table 2). Other authors could not demonstrate any correlation with disability measures $[64,66]$. In some studies CSF NF-L concentration did not correlate with gender or age $[61,64,66,67]$ or disease duration $[64,65]$, but in some reports CSF NF-L levels were found to increase with age [68]. Blood NF-L levels have not been reported to date (Table 1).

NF-M subunit has not been analysed so far in body fluids of MS patients.

In patients with optic neuritis (ON), the levels of NF$\mathrm{H}$ phosphorylated form $\left(\mathrm{NF}-\mathrm{H}^{\mathrm{SMI35}}\right)$ in plasma [71], or its hyperphosphorylated form in CSF $\left(\mathrm{NF}-\mathrm{H}^{\mathrm{SMI} 34}\right)$ [69], as well as CSF NF-H ${ }^{\text {SMI35 }}$ levels in CIS patients [25], were found to be significantly higher compared to controls (Table 1). Significantly higher CSF NF-H levels in MS patients than in control subjects (Table 1 ) were also reported in several recent studies (Table 1) [23, 54, 72], with higher [70], or significantly higher $[54,62]$ levels in patients with a progressive course. Opposite to these findings, no difference in CSF levels of this biomarker was found between RR, SP and primary progressive (PP) MS patients by Eikelenboom et al. [66]. In some studies, CSF NF-H levels correlated significantly with EDSS score both in CIS [25] and MS patients [54, 62]. 
TABLE 2: Biomarkers of neuroaxonal damage in patients with multiple sclerosis (MS) and/or clinically isolated syndrome suggestive of MS (CIS) in relation to clinical parameters.

\begin{tabular}{|c|c|c|c|c|c|c|}
\hline Biomarker & $\begin{array}{c}\text { Correlation } \\
\text { with } \\
\text { disability* }^{*}\end{array}$ & $\begin{array}{c}\text { Correlation } \\
\text { with disease } \\
\text { activity* }\end{array}$ & $\begin{array}{l}\text { Prediction of } \\
\text { CIS } \\
\text { conversion to } \\
\text { CDMS* }\end{array}$ & $\begin{array}{l}\text { Prediction of } \\
\text { future disease } \\
\text { course* }\end{array}$ & $\begin{array}{c}\text { Prediction of } \\
\text { future } \\
\text { disability* }\end{array}$ & $\begin{array}{c}\text { Prediction of } \\
\text { treatment } \\
\text { response* }\end{array}$ \\
\hline NF-L & $\begin{array}{l}4(308)+ \\
2(117)-\end{array}$ & $4(339)+$ & $1(38)+$ & $1(95)+$ & $3(308)+$ & - \\
\hline Anti-NF-L & $\begin{array}{l}3(180)+ \\
2(181)-\end{array}$ & - & - & - & - & - \\
\hline Anti-NF-M & $\begin{array}{l}1(47)+ \\
1(49)-\end{array}$ & - & - & - & - & - \\
\hline $\mathrm{NF}-\mathrm{H}$ & $\begin{array}{c}5(256)+ \\
2(81)-\end{array}$ & $\begin{array}{c}3(254)+ \\
1(30)-\end{array}$ & $1(52)+$ & $1(34)+$ & $3(86)+$ & $\begin{array}{c}1(30)^{* *}+ \\
1(32)+\end{array}$ \\
\hline Anti-NF-H & $\begin{array}{l}1(67)+ \\
1(51)-\end{array}$ & - & - & - & - & - \\
\hline Tubulin & $1(35)+$ & - & - & - & - & - \\
\hline Antitubulin & $\begin{array}{l}1(67)+ \\
2(81)-\end{array}$ & - & - & - & - & - \\
\hline Actin & $1(35)+$ & - & - & - & - & - \\
\hline Tau & $\begin{array}{c}1(90)+ \\
4(218)-\end{array}$ & $\begin{array}{l}3(179)+ \\
1(90)-\end{array}$ & $\begin{array}{c}1(52)^{* *}+ \\
1(53)-\end{array}$ & $1(32)+$ & $\begin{array}{l}1(32)+ \\
1(53)-\end{array}$ & - \\
\hline Amyloid $\beta 42$ & $1(21)-$ & $1(21)+$ & - & - & - & - \\
\hline BACE1 & - & - & - & - & $1(100)-$ & - \\
\hline NAA & $2(160)+$ & - & - & - & - & - \\
\hline Apo-E & - & - & - & - & - & - \\
\hline NSE & $\begin{array}{l}1(64)+ \\
2(87)-\end{array}$ & - & - & - & - & - \\
\hline GAP-43 & $1(49)^{* *}+$ & - & - & - & - & - \\
\hline 24S-OH-chol & $1(118)+$ & $2(206)+$ & - & - & - & - \\
\hline $14-3-3$ & $2(82)+$ & $1(38)+$ & $2(123)+$ & - & $2(101)+$ & - \\
\hline
\end{tabular}

${ }^{*}$ Number of positive $(+)$ or negative $(-)$ studies with total number of patients included (in brackets); **a tendency; CDMS: clinically definite MS; NF-L: neurofilament-light chain; Anti-NF-L: antibodies to NF-L; Anti-NF-M: antibodies to neurofilament-intermediate chain; NF-H: neurofilament-heavy chain; Anti-NF-H: antibodies to NF-H; BACE1: $\beta$-site amyloid precursor protein-cleaving enzyme 1; NAA: N-acetylaspartate; Apo-E: apolipoprotein-E; NSE: neuron-specific enolase; GAP-43: growth-associated protein 43; 24S-OH-chol: 24S-hydroxycholesterol.

CSF NF-H levels also significantly correlated with the ambulation index and the nine-hole-peg test scores [62], as well as with the MSSS [76]. In the latter study the degree of NF phosphorylation (ratio, hyperphosphorylated versus phosphorylated NF-H) was 8-fold higher in severely versus mildly disabled patients [76], whereas no correlation of NF-H levels with EDSS was found in some other studies in CSF [66] or plasma [77]. The highest CSF NF-H levels were found during relapses $[25,54]$ or correlated with MRI lesion enhancement [78], but Petzold et al. found no correlation of plasma $\mathrm{HF}-\mathrm{H}^{\mathrm{SMI} 35}$ with the relapse rate [77]. In the study of Brettschneider et al., the sensitivity for predicting conversion to clinically definite (CD) MS after CIS was generally low, but could be increased by combining MRI with CSF NF-H criteria [25]. Additionally, a tendency towards a higher RRMS to SPMS conversion rate over 3 years in patients with high CSF NF-H levels was also shown [62]. Moreover, Petzold et al. [71] found significantly higher plasma NF-H levels in ON patients with poor recovery of visual acuity than in those with good recovery. In the study of Lim et al., in which $8 / 18$ patients in the ON trial and $15 / 32$ subjects in the MS attack trial were treated with oral methylprednisolone, in the MS attack trial group, CSF NF- $\mathrm{H}^{\mathrm{SMI} 34}$ and NF-H $\mathrm{H}^{\mathrm{SMI} 35}$ measured at week 3 and CSF NF-H ${ }^{\text {SMI34 }}$ levels from baseline to week 3 were predictive of clinical outcome at week 8 and 52 [78]. In the study of Rejdak et al., CSF NF-H levels inversely correlated with the EDSS recovery grade over a short-term follow-up of 6-8 weeks [72]. Moreover, in 30 RRMS patients, plasma NF-H ${ }^{\mathrm{SMI} 35}$ levels were higher, albeit nonsignificantly, in nonresponders than in responders to IFN beta1-a or 1b over 1 year of treatment [77]. A correlation of CSF NF$\mathrm{H}$ levels with age was found in CIS or MS patients in some studies [54], but in the others no age influence $[62,66]$ or a correlation with disease duration was found $[66,72]$.

3.2. Antineurofilament Antibodies. Axonal damage and subsequent exposure of NFs could lead to antibody generation in a T-cell-dependent secondary immune response to a foreign antigen [85]. Cytoskeletal and myelin debris, released by 
TABLE 3: Parameters of humoral and cellular response to markers of neuroaxonal damage in the cerebrospinal fluid (CSF) and blood of patients with multiple sclerosis (MS) and clinically isolated syndrome suggestive of MS (CIS).

\begin{tabular}{|c|c|c|c|c|c|}
\hline Biomarker & Body fluid & Immunoassay & Number of patients & Main findings & REF \\
\hline \multirow{4}{*}{ Anti-NF-L } & $\mathrm{CSF} / \mathrm{SE}$ & ELISA (IgG) & $67 \mathrm{MS}(\mathrm{RR} / \mathrm{SP} / \mathrm{PP})$ & $\begin{array}{c}\text { CSF/SE index in PP or SP } \\
\uparrow \uparrow \mathrm{RR} \text { or } \\
\text { OIND/NIND/NHCo }\end{array}$ & {$[74]$} \\
\hline & CSF/SE & ELISA (IgM, IgG) & $\begin{array}{c}58 \mathrm{MS}(\mathrm{RR} / \mathrm{SP} / \mathrm{PP}) \\
+8 \mathrm{CIS}\end{array}$ & $\begin{array}{c}\text { specific IgG-index in } \mathrm{MS} \uparrow \uparrow \\
\mathrm{CD}\end{array}$ & [79] \\
\hline & CSF/SE & ELISA (IgG) & $51 \mathrm{MS}(\mathrm{RR} / \mathrm{SP} / \mathrm{PP})$ & $\begin{array}{c}\text { CSF/SE index correlated } \\
\text { with brain atrophy, RR } \leftrightarrow \\
\mathrm{SP} \leftrightarrow \mathrm{PP}\end{array}$ & [66] \\
\hline & $\mathrm{CSF} / \mathrm{SE}$ & ELISA (IgG) & $\begin{array}{c}130 \mathrm{MS} \\
(\mathrm{RR} / \mathrm{SP} / \mathrm{PP})\end{array}$ & $\begin{array}{c}\text { serum antibody levels in PP } \\
\uparrow \uparrow \text { OND or HCo }\end{array}$ & [80] \\
\hline \multirow{2}{*}{ Anti-NF-M } & $\mathrm{CSF} / \mathrm{SE}$ & ELISA (IgG) & $47 \mathrm{MS}(\mathrm{RR} / \mathrm{SP} / \mathrm{PP})$ & $\begin{array}{l}\text { significant correlation with } \\
\text { anti-NF-L and antitubulin } \\
\text { IgG in serum and CSF }\end{array}$ & {$[81]$} \\
\hline & $\mathrm{CSF} / \mathrm{SE}$ & ELISA (IgG, IgM) & $49 \mathrm{MS}(\mathrm{RR} / \mathrm{SP} / \mathrm{PP})$ & $\begin{array}{c}\text { IgM and IgG specific } \\
\text { indices in MS subgroups } \uparrow \uparrow \\
\mathrm{CD} \text { or } \mathrm{CN}\end{array}$ & [82] \\
\hline \multirow{2}{*}{ Anti-NF-H } & CSF/SE & ELISA (IgG) & $51 \mathrm{MS}(\mathrm{RR} / \mathrm{SP} / \mathrm{PP})$ & $\mathrm{RR} \leftrightarrow \mathrm{SP} \leftrightarrow \mathrm{PP}$ & {$[66]$} \\
\hline & $\mathrm{CSF} / \mathrm{SE}$ & ELISA (IgG) & $67 \mathrm{MS}(\mathrm{RR} / \mathrm{SP} / \mathrm{PP})$ & $\mathrm{MS} \leftrightarrow \mathrm{OIND} / \mathrm{NIND} / \mathrm{NHCo}$ & {$[74]$} \\
\hline \multirow{3}{*}{ Antitubulin } & $\mathrm{CSF} / \mathrm{SE}$ & ELISA (IgG) & $67 \mathrm{MS}(\mathrm{RR} / \mathrm{SP} / \mathrm{PP})$ & $\mathrm{MS} \leftrightarrow \mathrm{OIND} / \mathrm{NIND} / \mathrm{NHCo}$ & {$[74]$} \\
\hline & $\mathrm{CSF} / \mathrm{SE}$ & ELISA (IgG) & $47 \mathrm{MS}(\mathrm{RR} / \mathrm{SP} / \mathrm{PP})$ & $\begin{array}{l}\text { significant correlation with } \\
\text { anti-NF-L and anti-NF-M } \\
\text { IgG in serum and CSF }\end{array}$ & {$[81]$} \\
\hline & $\mathrm{CSF} / \mathrm{SE}$ & ELISA (IgG) & $\begin{array}{l}29 \mathrm{MS}(\mathrm{RR} / \mathrm{SP} / \mathrm{PP}) \\
+5 \mathrm{CIS}\end{array}$ & $\begin{array}{c}\text { CSF levels in MS+CIS } \uparrow \uparrow \\
\mathrm{CN}\end{array}$ & {$[83]$} \\
\hline $\begin{array}{l}\text { Anti-NSE } \\
\text { T-cell } \\
\text { response }\end{array}$ & PBMC & $\begin{array}{c}\text { T-cell } \\
\text { Proliferation } \\
\text { Assay }\end{array}$ & $35 \mathrm{MS}$ & $\begin{array}{c}\text { prevalence of response in } \\
\text { MS } \uparrow \mathrm{HCo}\end{array}$ & {$[84]$} \\
\hline
\end{tabular}

REF: reference; Anti-NF-L: antibodies to neurofilament-light chain; anti-NF-M: antibodies to neurofilament-intermediate chain; anti-NF-H: antibodies to neurofilament-heavy chain; NSE: neuron-specific enolase; SE: serum; PBMC: peripheral blood mononuclear cells; ELISA: Enzyme-Linked Immunosorbent Assay; IgG: immunoglobulin G, IgM: immunoglobulin M; RR: relapsing-remitting MS; SP: secondary-progressive MS; PP: primary-progressive MS; $\uparrow \uparrow$ significantly higher than; $\leftrightarrow$ no difference between; OIND: other inflammatory neurological diseases; NIND: noninflammatory neurological disorders; NHCo: neurologically healthy controls; CD: miscellaneous neurological diseases; OND: other neurological diseases; HCo: healthy controls, CN: normal controls (vertigo, headache, psychogenic syndrome, and fatigue).

neurons, are removed by macrophages which may be able to reach the peripheral lymph nodes [86]. Additionally, antiNF-antibodies could be induced from exposure to exogenous agents, possibly virus-derived peptides and subseqently may cross-react with neuronal antigens [87].

Autoimmune responses to neuronal antigens might contribute to axonal damage and irreversible disability in MS [12], but could also be an epiphenomenon [79]. In the latter study, intrathecal immunoglobulin (Ig) G and IgM anti-NF-L synthesis did not differ between MS subgroups (RR, SP, or PP) or between CIS, MS patients, or healthy controls [79] (Table 3). On the other hand, the intrathecal anti-NF-L IgG was shown to correlate with MRI parameters of cerebral atrophy [66] and NF-L-autoimmunity has been also recently reported to be pathogenic in mice [12]. Additionally, anti-NF-L-IgG levels in serum were found to be significantly increased in PPMS patients compared to other neurological diseases or healthy controls [80] and in some studies a specific CSF/serum anti-NF-L IgG index correlated with EDSS or MSSS scores [74, 81] (Table 2). In some reports, anti-NF-L levels did not correlate with age or disease duration or EDSS score $[66,80]$, although some other authors showed a correlation between both anti-NF-L IgG index and CSF anti-NF-L IgG and duration of symptoms before lumbar puncture [74].

Anti-NF-M antibody response was analyzed in MS in a few studies. In a study of Bartoš et al., the extent of antiNF-M antibody levels did not correspond to any individualized clinical profiles of MS patients although the intrathecal production of IgM and IgG anti-NF-M was significantly increased in all MS subgroups compared to patients with other diseases or healthy controls [82] (Table 3). In the latter study [82], the intrathecal IgG and IgM anti-NF-M synthesis in MS patients was unrelated to gender, age, disease duration, and EDSS score, but Fialová et al. [81] found a correlation between anti-NF-M IgG intrathecal synthesis and disability.

Anti-NF-H IgG in CSF/serum was found to be similar in MS patients and controls [74] and between RR, SP, and PPMS patients [66] (Table 3). The intrathecal production of anti-NF-H IgG correlated with some parameters of brain 
atrophy such as the parenchymal fraction [74]. The CSF antiNF-H levels correlated with the duration of disease before lumbar puncture and EDSS score in the study of Silber et al. [74], but no correlation with EDSS was shown by others [66].

3.3. Tubulin and Antitubulin Antibodies. In addition to NFs, the other major component of the axonal cytoskeleton is the microtubule, which mainly consists of $\alpha$ and $\beta$ tubulin subunits [21], but also of microtubule-associated proteins (MAPs) such as MAP2 and tau [88]. Tubulin comprises as much as $20 \%$ of the cellular protein in brain [89] and is mainly responsible for axonal migration and longitudinal growth as well as for providing the conduit for fast axonal transport [90]. CSF tubulin levels were found to be increased in progressive $\mathrm{MS}(\mathrm{SP}+\mathrm{PP})$ patients as compared to RRMS or controls [63] (Table 4). Antitubulin antibodies were also investigated and in some studies CSF levels of these antibodies were shown to be increased in MS patients [83], a finding which was not shown by others [74]. CSF tubulin levels [63], but also CSF antibodies to tubulin and the CSF/serum antitubulin index correlated significantly with EDSS in one study [74], whereas no similar correlations with disability were found in two other studies [81, 83] (Table 2). No correlations of antitubulin antibodies were found with age or disease duration $[74,83]$.

3.4. Actin. Actin is the major component of the microfilaments [21]. CSF actin levels were found to be significantly elevated in MS patients than in the control group, with higher levels in progressive MS cases and correlated with the EDSS scores [63] (Table 4). Anti-actin antibodies were not separately investigated in MS patients to date and could also be detected in normal sera [91].

3.5. Gelsolin. Gelsolin is an actin-binding protein that regulates actin organization [92] and is expressed in neurons in addition to the other cells [93]. Additionally, its secreted isoform could be found in the circulation [94] and belongs to the extracellular actin scavenger system [95]. Following some preliminary results showing low blood and CSF gelsolin concentration in $4 \mathrm{MS}$ patients [92], Kulakowska et al. recently reported significantly lower plasma gelsolin levels in MS samples than in controls, whereas there was no difference in its CSF levels between the two groups [96] (Table 4).

3.6. Tau Protein. Tau is an axonal cytoskeletal protein that is involved in microtubule assembly and stabilisation [97] and therefore is essential for the efficient axonal transport [98]. Abnormal phosphorylation of tau can lead to the formation of potentially neurotoxic insoluble tau aggregates that have been shown to be characteristic features of common neurodegenerative diseases $[97,99,100]$. Pathological studies demonstrated the association of abnormally phosphorylated tau (p-tau) protein with SPMS and PPMS [101, 102] but also the absence of insoluble tau fraction in early MS, thus indicating the possibility that insoluble tau accumulates with disease progression $[100,102]$.
Total-tau ( $\mathrm{t}$-tau) protein and/or p-tau have been investigated in a respectable number of studies performed in CIS [25, 54, 103-106] and MS patients (Table 4) and the reported results are quite contradictory. Tau protein could be detectable in serum, but in concentrations that are ten times lower than in CSF [21]. CSF t-tau levels in CIS have been reported to be higher than in controls [25], but other authors found no difference in t-tau or p-tau compared to controls [104-106] (Table 4). In some MS studies, CSF levels of t-tau [103, 107-110] and p-tau [109] were reported to be significantly higher in MS patients than in controls, whereas some other authors could not confirm these differences $[54,104,111]$. T-tau and p-tau were also investigated in childhood RRMS cases in which their CSF levels were similar to controls [112]. A positive correlation of CSF t-tau levels was shown with EDSS in RRMS and CIS patients [25] and with the progression index over 3 years in early RRMS [113], but in some other studies no correlation with disability in CIS or MS was demonstrated for the CSF [103, 104, 110] or serum and CSF levels [105] (Table 2). Two studies have indicated an increased CSF-tau release in clinically active disease states $[109,114]$, in one study there was a significant elevation of CSF t-tau among patients with gadoliniumenhancing brain MRI lesions [103], but the latter finding was not confirmed afterwards [25]. However, the relation of CSF tau levels with the extent of intrathecal inflammation in MS was also supported by findings of Bartosik-Psujek and Archelos who showed a significant positive correlation between CSF t-tau levels and IgG index [108]. As shown by Brettschneider et al., the sensitivity and specificity of CSF tau levels for predicting CIS conversion to CDMS was generally low, but could be increased by combining with MRI parameters or with NF-H ${ }^{\text {SMI35 }}$ levels [25]. Gajofatto et al. [115] could not show a significant predictive value of CSF $\mathrm{t}$-tau in patients with acute myelitis either for conversion to MS or for disability after a median followup of 6.2 years, but in the study of Martínez-Yélamos et al. [113], CSF-t-tau was the only independent variable to predict time to the next relapse (Table 2). Interestingly, phosphorylation of tau and axonal pathology were significantly reduced when EAE rats were treated with prednisolone [116], but similar findings in MS were not reported. Although CSF t-tau levels were found associated with age in the control group in the study of Bartosik-Psujek and Archelos [108], no correlation of CSF t-tau/p-tau levels with age or disease duration was found in the majority of other studies $[104,106,107,110,111,117]$.

3.7. Amyloid-Precursor Protein and Related Molecules. Amyloid precursor protein (APP) probably works as a cargo receptor for binding proteins during axonal transport [21], but could have some other important neural functions including those in memory processes [118]. APP is transported by a fast anterograde axonal transport [119] and subtle changes in axonal transport or axonal transection could lead to APP deposits in the axon that are easily detectable by immunocytochemistry [120]. Based on immunopathological findings, it was suggested that APP accumulation could be a sensitive marker of MS disease 

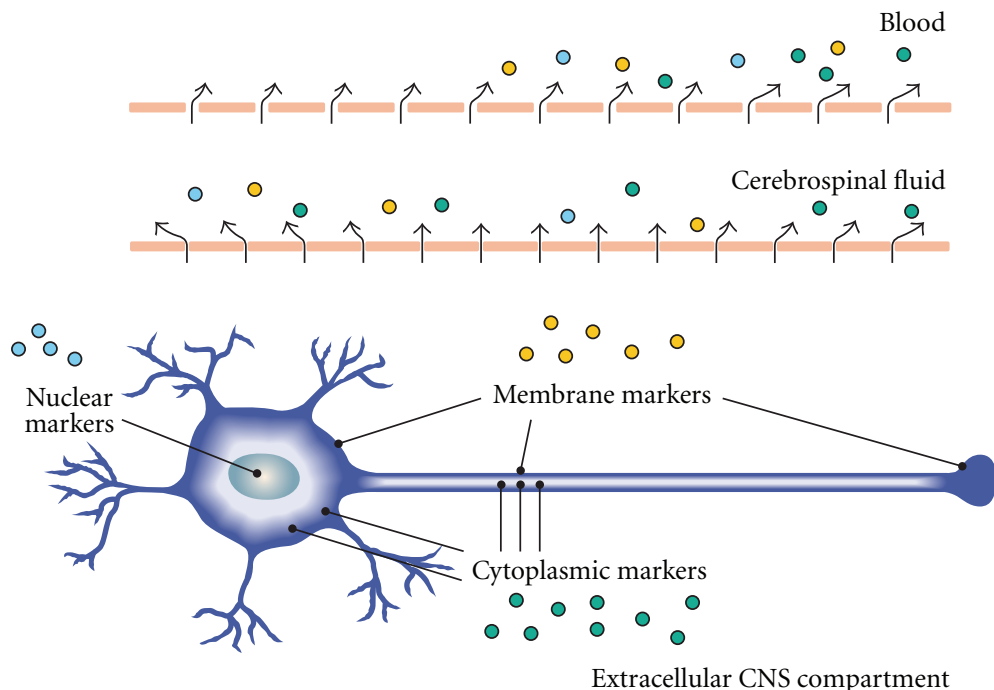

Figure 2: Membrane, cytoplasmic, and nuclear markers of neuroaxonal damage in the central nervous system (CNS) and their dynamics within three compartments (extracellular space, cerebrospinal fluid, and blood).

progression [121], but also a potential marker of acute or active MS [10]. APP is cleaved by an integral membrane aspartyl protease ( $\beta$-site APP-cleaving enzyme $1, \mathrm{BACE} 1)$, which results in the release of $\mathrm{N}$-terminal $\beta$-cleaved soluble APP ( $\beta$-sAPP). The $\mathrm{C}$-terminal fragment is further processed by $\gamma$-secretase to yield the amyloid beta $(\mathrm{A} \beta 42)$ and the APP intracellular domain [122]. APP can also undergo $\alpha$ secretase-mediated cleavage, which results in the release of the solubile $\alpha$-sAPP [123].

In the recent study of Mattsson et al. [122], CSF levels of $\alpha$-sAPP, $\beta$-sAPP, and A $\beta 42$ were significantly lower in MS patients than in controls and patients with ongoing or recent MS exacerbation had lower $\alpha$-sAPP levels than stable MS patients. CSF BACE1 activity was slightly reduced in patients with MS compared to controls and patients with SPMS tended to have lower BACE1 activity than patients with RRMS [122]. Baseline BACE1 activity did not predict change in EDSS score after 10 years (Table 2) but low BACE1 activity was associated with prolonged MS disease duration and disease severity. In contrast to controls, a reduction in BACE1 activity over 10 years was seen only in RRMS, whereas patients with SPMS displayed constantly low BACE1 activity levels [122]. Additionally, two molecules, Bri2 and Bri2-23 have been shown to interact with APP and regulate A $\beta 42$ cleavage and aggregation in vivo $[124,125]$. Recent findings revealed that CSF levels of Bri2-23, a peptide cleaved from Bri2, may be a biomarker of cerebellar/cognition dysfunction in progressive MS patients in which CSF Bri2-23 levels have been recently shown to be decreased [125]. In a recent study of Mori et al. [126], CSF A $\beta 42$ levels were significantly lower in cognitively impaired MS patients and were inversely correlated with MRI parameters of disease activity. On the contrary, Vališ et al. [106] found a significantly higher CSF A $\beta 42$ levels in MS patients compared to the control group (Table 4). No study has followed the effect of treatment on CSF-APP-derived proteins although some preliminary results in 16 nondemented, non-MS patients indicated a significant decrease in CSF A $\beta 42$ levels following corticosteroid treatment [127]. CSF A $\beta 42$ levels were not shown to correlate with age or disease duration $[122,126]$.

3.8. N-Acetylaspartate. N-Acetylaspartate (NAA) is the amino acid synthesized and almost exclusively localized in neurons [128] and is one of the most abundant molecules in the CNS [129]. Postmortem studies of spinal cords from MS patients related lower tissue concentrations of NAA to the lower axonal volume [8]. Several functions of NAA molecule in the CNS have been hypothesized, such as (a) an osmolite to remove water from neurons, (b) an acetate contributor in myelin sheath synthesis, (c) a mitochondrial energy source, (d) a precursor for $N$-acetylaspartyl glutamate, and (e) a ligand for certain metabotropic glutamate receptors [130]. Brain proton MR spectroscopy (MRS) allows in vivo examination of axonal integrity by quantifying the resonance intensity of NAA [131]. Previous proton MRS studies have found the reduced NAA levels in MS lesions, the surrounding NAWM and cortical grey matter [132], and a decline in global MRS-NAA levels was also demonstrated in benign MS [133]. A decrease in relative NAA levels by proton MRS was found in patients with CIS in CNS gray matter [134] and WM lesions [135]. Other studies have shown that NAA decrease in lesions and NAWM is related to clinical disability and progressive brain atrophy [136-138] and was indicated to be a feature of progression [16]. Moreover, some preliminary MRS findings have shown a beneficial effect of glatiramer acetate on increase of relative NAA peaks in MS lesions and NAWM over 2 years [131], whereas relative NAA peaks had become significantly higher in the interferon betalb -treated MS patients following 1 year of treatment [139].

In the study of Jasperse et al. [141], CSF concentrations of NAA correlated with EDSS and MS Functional Composite 
TABLE 4: Cytoplasmic, non-neurofilament biomarkers of neuroaxonal damage in the cerebrospinal fluid (CSF) and blood of patients with multiple sclerosis (MS) and/or clinically isolated syndrome suggestive of MS (CIS).

\begin{tabular}{|c|c|c|c|c|c|}
\hline Biomarker & Body fluid & Immunoassay & Number of patients & Main findings & REF \\
\hline Tubulin & CSF & Dot-blot & $35 \mathrm{MS}(\mathrm{RR} / \mathrm{SP} / \mathrm{PP})$ & $\begin{array}{c}\mathrm{MS} \uparrow \uparrow \text { OIND or NIND, PP/SP } \uparrow \uparrow \\
\mathrm{RR}\end{array}$ & {$[63]$} \\
\hline Actin & CSF & Dot-blot & $35 \mathrm{MS}(\mathrm{RR} / \mathrm{SP} / \mathrm{PP})$ & $\begin{array}{c}\text { MS } \uparrow \uparrow \text { OIND or NIND, PP/SP } \uparrow \uparrow \\
\text { RR } \\
\end{array}$ & {$[63]$} \\
\hline Gelsolin & $\mathrm{CSF} / \mathrm{PL}$ & Western blot & $56 \mathrm{MS}$ & $\begin{array}{c}\text { PL levels in MS } \downarrow \downarrow \mathrm{Co}^{*}, \mathrm{CSF} \\
\text { levels in MS } \leftrightarrow \mathrm{Co}^{*}\end{array}$ & {$[96]$} \\
\hline \multirow{13}{*}{ Tau } & CSF & $\operatorname{ELISA}(\mathrm{t}-\mathrm{t})$ & $38 \mathrm{MS}(\mathrm{RR})+52 \mathrm{CIS}$ & $\mathrm{CIS} \uparrow \uparrow \mathrm{NHCo}$ & {$[25]$} \\
\hline & CSF & $\operatorname{ELISA}(\mathrm{t}-\mathrm{t})$ & $45 \mathrm{MS}(\mathrm{RR} / \mathrm{SP} / \mathrm{PP})$ & $\begin{aligned} \mathrm{MS} \uparrow \uparrow \mathrm{OIND} & +\mathrm{NIND}, \mathrm{SP} \leftrightarrow \mathrm{RR} \\
& \leftrightarrow \mathrm{PP}\end{aligned}$ & {$[110]$} \\
\hline & CSF & $\operatorname{ELISA}(t-t, p-t)$ & 42 RRMS + 18 CIS & $\begin{array}{l}\mathrm{t} \text {-tau and p-tau in MS+CIS } \uparrow \\
\text { NHCo, t-tau in CIS } \uparrow \uparrow \mathrm{NHCo}\end{array}$ & [109] \\
\hline & $\mathrm{CSF}$ & $\operatorname{ELISA}(\mathrm{t}-\mathrm{t})$ & $\begin{array}{c}38 \mathrm{MS}(\mathrm{RR} / \mathrm{SP} / \mathrm{PP})+ \\
12 \mathrm{CIS}\end{array}$ & $\mathrm{MS}+\mathrm{CIS} \leftrightarrow \mathrm{NHCo}$ & [104] \\
\hline & CSF & $\operatorname{ELISA}(t-t)$ & $\begin{array}{c}76 \mathrm{MS}(\mathrm{RR} / \mathrm{SP} / \mathrm{PP})+ \\
38 \mathrm{CIS}\end{array}$ & $\mathrm{MS} / \mathrm{CIS} \leftrightarrow \mathrm{NHCo}$ & {$[54]$} \\
\hline & CSF & $\operatorname{ELISA}(t-t)$ & $114 \mathrm{MS}(\mathrm{RR} / \mathrm{SP} / \mathrm{PP})$ & $\mathrm{MS} \uparrow \uparrow \mathrm{NIND}$ & [108] \\
\hline & CSF & $\operatorname{ELISA}(\mathrm{t}-\mathrm{t})$ & $\begin{array}{c}52 \mathrm{MS}(\mathrm{RR} / \mathrm{SP} / \mathrm{PP})+ \\
50 \mathrm{CIS}\end{array}$ & $\begin{array}{c}\text { MS+CIS } \uparrow \uparrow \text { NHCo, the highest } \\
\text { in CIS }\end{array}$ & [103] \\
\hline & $\mathrm{CSF}$ & $\operatorname{ELISA}(\mathrm{t}-\mathrm{t})$ & $\begin{array}{c}20 \mathrm{MS} \\
(\mathrm{RR} / \text { progressive MS) }\end{array}$ & $\mathrm{MS} \leftrightarrow \mathrm{NHCo}$ & {$[111]$} \\
\hline & CSF & $\operatorname{ELISA}(\mathrm{t}-\mathrm{t})$ & $36 \mathrm{MS}(\mathrm{RR} / \mathrm{SP} / \mathrm{PP})$ & $\mathrm{MS} \uparrow \uparrow \mathrm{NHCo}$ & [107] \\
\hline & CSF & $\operatorname{ELISA}(t-t, p-t)$ & 25 RRMS & $\mathrm{MS} \leftrightarrow \mathrm{OIND}$ or NIND & {$[112]$} \\
\hline & $\mathrm{CSF} / \mathrm{SE}$ & $\operatorname{ELISA}(t-t, p-t)$ & 21 CIS & $\mathrm{CIS} \leftrightarrow \mathrm{Co}^{* *}$ & {$[105]$} \\
\hline & CSF & $\operatorname{ELISA}(t-t, p-t)$ & $14 \mathrm{MS}+9 \mathrm{CIS}$ & $\mathrm{MS} \leftrightarrow \mathrm{CIS} \leftrightarrow \mathrm{NHCo}$ & {$[106]$} \\
\hline & CSF & $\operatorname{ELISA}(\mathrm{t}-\mathrm{t})$ & $\begin{array}{c}43 \mathrm{MS} \\
(\mathrm{RR} / \mathrm{SP} / \mathrm{PP} / \mathrm{PR})+20 \\
\mathrm{CIS} \\
\end{array}$ & $\mathrm{MS} \leftrightarrow \mathrm{CIS} \leftrightarrow \mathrm{NHCo}+\mathrm{OND}$ & {$[140]$} \\
\hline Amyloid $\beta 42$ & $\mathrm{CSF} / \mathrm{SE}$ & ELISA & $21 \mathrm{CIS}$ & $\mathrm{CIS} \leftrightarrow \mathrm{Co}^{* *}$ & {$[105]$} \\
\hline Amyloid $\beta 42$ & CSF & ELISA & $14 \mathrm{MS}+9$ CIS & $\mathrm{MS} \uparrow \uparrow \mathrm{NHCo}$ & [106] \\
\hline Amyloid $\beta 42$ & CSF & xMAP & $100 \mathrm{MS}(\mathrm{RR} / \mathrm{SP} / \mathrm{PP})$ & MS $\downarrow$ NHCo & {$[122]$} \\
\hline$\alpha$-sAPP & CSF & Multiplex Assay & $100 \mathrm{MS}(\mathrm{RR} / \mathrm{SP} / \mathrm{PP})$ & $\mathrm{MS} \downarrow \downarrow \mathrm{NHCo}$ & {$[122]$} \\
\hline$\beta$-sAPP & CSF & Multiplex Assay & $100 \mathrm{MS}(\mathrm{RR} / \mathrm{SP} / \mathrm{PP})$ & $\mathrm{MS} \downarrow \downarrow \mathrm{NHCo}$ & {$[122]$} \\
\hline Bri2-23 & CSF & SELDI-TOF & $40 \mathrm{MS}(\mathrm{SP} / \mathrm{PP})$ & MS $\downarrow$ OND & {$[125]$} \\
\hline \multirow[t]{2}{*}{ NAA } & $\mathrm{CSF}$ & GC-MS & $\begin{array}{c}76 \mathrm{MS}(\mathrm{RR} / \mathrm{SP} / \mathrm{PP})+ \\
38 \mathrm{CIS}\end{array}$ & $\begin{array}{c}\mathrm{SP} \downarrow \downarrow \mathrm{RR} / \mathrm{CIS}, \mathrm{CIS} \leftrightarrow \mathrm{RR} \leftrightarrow \\
\mathrm{NHCo}\end{array}$ & {$[54]$} \\
\hline & CSF & GC-MS & $46 \mathrm{MS}(\mathrm{RR} / \mathrm{SP} / \mathrm{PP})$ & $\mathrm{MS} \leftrightarrow \mathrm{OND}, \mathrm{SP} \downarrow \downarrow \mathrm{RR}$ & [141] \\
\hline \multirow{5}{*}{ NSE } & CSF & Luminescence & $66 \mathrm{MS}$ (RR/SP) & $\mathrm{MS} \leftrightarrow \mathrm{HCo}$ & {$[64]$} \\
\hline & SE & RIA & $21 \mathrm{MS}$ & levels within normal range & [142] \\
\hline & $\mathrm{PL}$ & Luminescence & $64 \mathrm{MS}(\mathrm{RR} / \mathrm{SP} / \mathrm{PP})$ & progressive MS $\downarrow$ RR & {$[143]$} \\
\hline & $\mathrm{CSF} / \mathrm{SE}$ & ELISA & $21 \mathrm{CIS}$ & $\mathrm{CIS} \downarrow \mathrm{Co}^{* *}$ & {$[105]$} \\
\hline & CSF & Immunoluminometry & 33MS (RR/SP) & $\mathrm{RR} \leftrightarrow \mathrm{SP}$ & [144] \\
\hline
\end{tabular}

REF: reference; APP: amyloid-precursor protein; NAA: N-acetylaspartate; NSE: neuron-specific enolase; SE: serum; PL: plasma; ELISA: Enzyme-Linked Immunosorbent Assay; t-t: total tau protein, p-t: abnormally phosphorylated tau protein; xMAP: xMap Bead-based immunoassay; SELDI-TOF: SurfaceEnhanced Laser Desorption/Ionization Time-Of-Flight; GC-MS: stable isotope dilution gas chromatography-mass spectrometry; RIA: radioimmunoassay; RR: relapsing-remitting MS; SP: secondary-progressive MS; PP: primary-progressive MS; $\uparrow \uparrow$ significantly higher than; $\downarrow \downarrow$ significantly lower than; $\downarrow$ lower than; $\leftrightarrow$ no difference between; OIND: other inflammatory neurological diseases; NIND: noninflammatory neurological disorders; Co: controls with *idiopathic headache, Bell's palsy and ischialgia or **idiopathic headache and migraine; NHCo: neurologically healthy controls; OND: other neurological diseases; HCo: healthy controls. 
(MSFC) (Table 2), although these levels were similar to controls both in MS [141] and early MS patients [54]. CSF NAA levels were shown to be lower in SPMS patients compared to RR and PPMS cases [54, 141] (Table 4). Teunissen et al. reported a decrease in CSF NAA levels as the disease progressed, therefore possibly reflecting the accumulation of axonal degeneration in a later MS stage [54]. One study has shown CSF NAA concentrations to correlate with age [54].

3.9. Apolipoprotein E. Apolipoprotein E (Apo-E) is mostly produced by astrocytes in the CNS, but it is also found in neurons [21]. There are three different alleles of the human Apo-E gene coding for the three isoforms: $\varepsilon 2, \varepsilon 3$, and $\varepsilon 4$ [145]. Apo-E is generally involved in lipid transport and cholesterol homeostasis [21]. However, its functions within the CNS are not so clear and might include immunomodulation, a protective role against oxidative stress [146], a role in maintaining the BBB integrity [147], a role in myelin lipid metabolism [148], and a potential role in neurorepair [21]. As there is a limited permeability of Apo- $\mathrm{E}$ across the $\mathrm{BBB}, \mathrm{Apo}-\mathrm{E}$ changes in CSF might dominantly result from a reduction of its local synthesis and secretion by brain tissue $[146,149]$.

Several studies have indicated that Apo-E \&4 allele might be associated with MS, although evidence is still not sufficient enough [146, 150]. Although plausible [151], the association between Apo-E and MS course and disease severity remains controversial [152]. Apo-E genotypes seem not to influence the development of MS, but Apo-E $\varepsilon 4$ allele might predispose carriers with MS to a faster disease progression $[153,154]$. In line with this, lower levels of NAA in MS patients with the Apo-E $\varepsilon 4$ allele have been demonstrated by MRS [155]. It has been recently suggested that ApoE polymorphism may interact with cigarette smoking in promoting MS progression [156]. Although some authors have shown an association between Apo-E $\varepsilon 4$ and cognitive impairment in MS patients [157], the others could not confirm this finding [158].

However, it was suggested that the decreased CSF Apo-E concentration in MS patients occurs independent of the Apo-E genotype [159]. In one study the plasma concentration of Apo-E was significantly lower in MS patients than in healthy controls although its CSF concentrations were similar in these two groups [148]. Rifai et al. have shown higher CSF/serum Apo-E index in RRMS in remission compared to controls [160], Chiasserini et al. demonstrated an increased CSF expression of an Apo-E isoform in RRMS compared to CIS patients or controls [161], whereas Gaillard et al. [159] found lower concentrations of both CSF Apo-E and intrathecal Apo-E in MS patients than in controls (Table 5). No correlation of Apo-E in serum or CSF with age or clinical course was found [159].

3.10. Neuron-Specific Enolase. Enolase is a glycolytic enzyme (2-phospho-D-glycerate hydrolase), which exists in three isoforms: $\alpha$-enolase, which is ubiquitous, $\beta$-enolase, which is predominant in muscle, and $\gamma$-enolase (neuron-specific enolase, NSE), which is found in neurons, glial, and neuroendocrine cells [84]. NSE was shown to be an indicator of the acute neuro-destructive disorders [162], but its levels are usually normal in MS patients [162] and no clear difference in the NSE levels has been observed between MS patients and controls in CSF [64] or serum [142], or between patients with RR and SPMS in CSF [144] (Table 4). NSE concentration in CSF and serum was shown to be decreased in CIS patients when compared to the control group, potentially indicating a reduced neuronal metabolic activity at the early stage of the disease [105]. Interestingly, Forooghian et al. demonstrated a higher T-cell responses against NSE in the peripheral blood mononuclear cells of MS patients than in controls [84]. One study which followed CSF NSE levels in MS patients treated with intrathecal triamcinolone administration did not show any changes in its levels following treatment [163]. A recent study examined plasma NSE levels in MS patients over a five-year period and found a strong inverse relationship between serum NSE levels and disease progression [143] as expressed through EDSS and MSSS score changes, thus potentially reflecting a reduced metabolic activity secondary to axonal loss. In two other studies no correlation of CSF $[64,105]$ or serum [105] NSE levels were found with EDSS (Table 2). Age-related changes of NSE in CSF with an increase of $1 \%$ per year have been reported [164], but in some other studies CSF NSE levels were independent of gender, age $[64,165]$, and disease duration [64].

3.11. Growth-Associated Protein 43. Growth-associated protein 43 (GAP-43), also known as B-50 or neuromodulin, is a marker associated with growth cones, synaptic plasticity, and synaptic regeneration [166]. It is a calmodulin-binding protein being attached to the cytoplasmic site of the axonal membrane, involved in neurotransmitter release [167] which also stimulates neurite outgrowth [166]. A decreased GAP-43 expression was found in postmortem white matter MS lesions, independent of the lesion stage, whereas increased or unaltered expression was detected in remyelinated lesions and was found unchanged in grey matter lesions [167].

In a recent study, CSF GAP-43 levels were comparable among RR/SP and PPMS subtypes and controls and GAP43 was not detected in serum [167] (Table 5). A tendency towards a negative correlation between CSF GAP-43 levels and EDSS was found, but CSF GAP 43 levels positively correlated with MRI measures of atrophy [167] (Table 2). Moreover, a positive correlation was observed between CSF NAA and GAP-43 levels [141]. No significant correlation was reported between CSF GAP-43 levels and age, gender, and disease duration [167].

3.12. 24S-Hydroxycholesterol. Cholesterol plays a crucial structural role in the brain [168] being the main lipid of neuronal membranes [21]. For maintenance of brain cholesterol homeostasis [168], cholesterol is converted into its more polar metabolite cerebrosterol (24S-hydroxycholesterol, 24S$\mathrm{OH}$-chol) by the CNS-specific cytochrome P450 enzyme CYP46 [169]. Virtually all of the cerebrosterol in the 
TABLE 5: Membrane and nuclear biomarkers of neuroaxonal damage in the cerebrospinal fluid (CSF) and blood of patients with multiple sclerosis (MS) and/or clinically isolated syndrome suggestive of MS (CIS).

\begin{tabular}{|c|c|c|c|c|c|}
\hline $\begin{array}{l}\text { Biomarker } \\
\text { (subtype) }\end{array}$ & Body fluid & Immunoassay & Number of patients & Main findings & REF \\
\hline $\begin{array}{l}\text { BACE1 } \\
\text { (membrane) }\end{array}$ & CSF & Enzymatic & $100 \mathrm{MS}(\mathrm{RR} / \mathrm{SP} / \mathrm{PP})$ & MS slightly $\downarrow$ NHCo & {$[122]$} \\
\hline \multirow{3}{*}{$\begin{array}{l}\text { Apo-E } \\
\text { (membrane) }\end{array}$} & $\mathrm{CSF} / \mathrm{SE}$ & Immunofluorometry & $34 \mathrm{MS}$ & CSF levels in MS $\downarrow \downarrow$ NHCo & [159] \\
\hline & CSF & 2DE-MS & 10 RRMS + 11 CIS & $\begin{array}{l}\text { one isoform expression in } \mathrm{RR} \uparrow \uparrow \\
\text { CIS or NHCo }\end{array}$ & {$[161]$} \\
\hline & $\mathrm{CSF} / \mathrm{SE}$ & Immunoturbidimetry & $33 \mathrm{MS}(\mathrm{RR})$ & $\begin{array}{c}\mathrm{CSF} / \text { serum index in MS in } \\
\text { remission } \uparrow \uparrow \mathrm{NHCo}\end{array}$ & {$[160]$} \\
\hline \multirow{2}{*}{$\begin{array}{l}\text { GAP- } 43 \\
\text { (membrane) }\end{array}$} & $\mathrm{CSF} / \mathrm{SE}$ & xMap Bead -based & $49 \mathrm{MS}(\mathrm{RR} / \mathrm{SP} / \mathrm{PP})$ & $\begin{array}{c}\mathrm{CSF} \text { in } \mathrm{RR} \leftrightarrow \mathrm{SP} \leftrightarrow \mathrm{PP} \leftrightarrow \mathrm{OIND} \\
+\mathrm{NIND}+\mathrm{HCo}, \text { not detected in } \\
\text { serum }\end{array}$ & {$[167]$} \\
\hline & CSF & xMap Bead -based & $44 \mathrm{MS}(\mathrm{RR} / \mathrm{SP} / \mathrm{PP})$ & $\begin{array}{l}\text { significant positive correlation } \\
\text { with NAA levels }\end{array}$ & {$[141]$} \\
\hline \multirow{5}{*}{$\begin{array}{l}\text { 24S-OH-chol } \\
\text { (membrane) }\end{array}$} & PL & IDMS & $46 \mathrm{MS}(\mathrm{RR} / \mathrm{PP})$ & $\begin{array}{c}\text { negative correlation with T2 } \\
\text { lesion volume }\end{array}$ & {$[169]$} \\
\hline & PL & IDMS & $11 \mathrm{MS}$ & $\mathrm{MS} \leftrightarrow \mathrm{HCo}$ & {$[170]$} \\
\hline & $\mathrm{CSF} / \mathrm{PL}$ & IDMS & $118 \mathrm{MS}(\mathrm{RR} / \mathrm{SP} / \mathrm{PP})$ & PL levels in older MS $\downarrow \downarrow \mathrm{HCo}$ & {$[171]$} \\
\hline & SE & IDMS & $60 \mathrm{MS}(\mathrm{RR} / \mathrm{SP} / \mathrm{PP})$ & $\mathrm{PP}$ or older RR $\downarrow \mathrm{HCo}$ & {$[172]$} \\
\hline & $\mathrm{CSF} / \mathrm{PL}$ & IDMS & $88 \mathrm{MS}$ & PL levels in MS $\leftrightarrow \mathrm{Co}$ & [173] \\
\hline \multirow{6}{*}{$\begin{array}{l}\text { Protein } 14-3-3 \\
\text { (cytoplasmic, nuclear, } \\
\text { membrane) }\end{array}$} & CSF & Western blot & $\begin{array}{c}22 \mathrm{MS}(\mathrm{RR} / \mathrm{SP} / \mathrm{PP})+ \\
15 \mathrm{ATM}\end{array}$ & $\begin{array}{l}\text { detected in about } 8 \% \text { RR/ATM } \\
\text { patients }\end{array}$ & {$[174]$} \\
\hline & CSF & Immunoblot & 38 CIS & detected in $13 \%$ CIS patients & {$[175]$} \\
\hline & $\mathrm{CSF} / \mathrm{SE}$ & Immunoblot & $21 \mathrm{CIS}$ & detected in $1 / 21$ patient & {$[105]$} \\
\hline & CSF & ELISA & $114 \mathrm{MS}(\mathrm{RR} / \mathrm{SP} / \mathrm{PP})$ & $\begin{array}{c}\text { detected in } 22 \% \text { MS patients, not } \\
\text { detected in HCo }\end{array}$ & {$[108]$} \\
\hline & CSF & Immunoblot & $\begin{array}{c}43 \mathrm{MS} \\
(\mathrm{RR} / \mathrm{SP} / \mathrm{PP} / \mathrm{PR})+20 \\
\mathrm{CIS}\end{array}$ & $\begin{array}{l}\text { detected in } 38 \% \text { CIS/MS, similar } \\
\text { in MS subgroups }\end{array}$ & {$[140]$} \\
\hline & CSF & Immunoblot & 85 CIS & detected in $8.2 \%$ CIS patients & {$[176]$} \\
\hline
\end{tabular}

REF: reference; BACE1: $\beta$-site amyloid precursor protein-cleaving enzyme 1; Apo-E: Apolipoprotein-E; GAP-43: growth-associated protein-43; $24 \mathrm{~S}-\mathrm{OH}-\mathrm{chol}$ : 24S-hydroxycholesterol; SE: serum; PL: plasma; Enzymatic: Enzymatic solution-based assay; 2DE-MS: two-dimensional electrophoresis-mass spectrometry; IDMS: isotope-dilution mass spectrometry; ELISA: Enzyme-Linked Immunosorbent Assay; RR: relapsing-remitting MS; SP: secondary-progressive MS; PP: primary-progressive MS; ATM: acute transverse myelitis; NAA: N-acetylaspartate; $\downarrow$ lower than; $\downarrow \downarrow$ significantly lower than; $\uparrow \uparrow$ significantly higher than; $\leftrightarrow$ no difference between; NHCo: neurologically healthy controls; OIND: other inflammatory neurological diseases; NIND: noninflammatory neurological disorders; HCo: healthy controls; Co: controls with idiopathic headache.

peripheral circulation is CNS derived and its blood levels are assumed to reflect the relation between cholesterol CNS production caused by demyelination or neurodegeneration and hepatic clearance $[170,177,178]$. The level of $24 S-$ $\mathrm{OH}$-chol highly correlated with total cholesterol and the ratio between $24 \mathrm{~S}-\mathrm{OH}$-chol and cholesterol is assumed to be a better marker for the cerebral production than the absolute cerebrosterol concentration [171]. The majority of daily efflux of this oxysterol from the brain to the circulation apparently occurs as a direct transport across the BBB and less than $1 \%$ of the total flux of $24 \mathrm{~S}-\mathrm{OH}$-chol from the brain occurs via CSF [168], which might cause the lack of correlation between CSF and plasma levels of this metabolite [171].

The higher CSF levels of 24S-OH-chol were shown in patients with gadolinium-enhancing MRI lesions, indicating the pronounced release of the $24 \mathrm{~S}-\mathrm{OH}$-chol from damaged cells during CNS inflammation $[171,173]$ (Table 2). Moreover, patients with a defective $\mathrm{BBB}$ were found to have markedly increased absolute levels of 24-OH-chol in CSF [179]. Karrenbauer et al. [169] demonstrated a negative correlation between the cerebrosterol/cholesterol ratio in plasma and volume of $\mathrm{T}_{2}$-weighted MRI lesions, whereas a significant inverse relation between the EDSS score and plasma cholesterol-related levels of $24 \mathrm{~S}-\mathrm{OH}$-chol was found in the other study [171]. Teunissen et al. [172] showed the reduction in serum $24 \mathrm{~S}-\mathrm{OH}$-chol concentrations to be most pronounced in the PP clinical subtype (Table 5). Leoni et al. found a tendency to increased plasma levels of $24 \mathrm{~S}-\mathrm{OH}$-chol in younger patients with high levels in the 3rd and 4th decades of life, and significantly lower levels in older MS patients aged 51-70 years than in healthy age-matched controls [171]. There seems to be no gender influence on plasma levels of 24S-OH-chol or the ratio 
between cerebrosterol/cholesterol [171] and no correlation of the latter with disease duration was reported to date [172].

3.13. Protein 14-3-3. 14-3-3 family proteins are ubiquitous, highly conserved proteins with the highest concentrations in brain $[162,180]$ and within CNS are constitutively expressed in neurons and glia both in cytoplasmic and nuclear regions [181] with small amounts bound to synaptic membranes [162]. A growing body of evidence indicates that it might act as a novel type of molecular chaperone which interacts with key molecules involved in cell differentiation, proliferation, and transformation [182], and recent data suggested its antiapoptotic effects $[183,184]$. The detection of 14-3-3 protein in the CSF is highly sensitive for in vivo diagnosis of Creutzfeldt-Jakob disease [185], but this protein, in the CSF, could be also detected in some other prion-unrelated conditions associated with CNS tissue damage [175, 181, 186].

The 14-3-3 protein is more frequently detectable in the CSF of MS or CIS patients than in controls although in such cases it is present in a small subgroup of patients [108, 174]. However, in the study of Colucci et al. [140] it was more frequently positive than previously reported (Table 5). The detection of the 14-3-3 protein in the CSF of CIS patients was shown to be an independent predictor of short-term conversion to CDMS $[175,176]$ (Table 2). Moreover, the 143-3 positive group had a significantly higher relapse rate and a higher frequency of patients with EDSS $\geq 2.0$ after a median followup of 33.4 months [176], which confirmed previous results by the same authors [175]. In some studies, 14-3-3 protein positivity in MS patients was associated with a more severe disability $[140,187]$ and the rate of disease progression during a mean of 10-month clinical followup [140], but was also shown to be a potential predictor of permanent neurological disability after an episode of the acute transverse myelitis [188]. However, the latter was not shown in two other studies $[115,174]$. The presence of 14-3-3 reactivity was not shown to prevail in MS clinical subgroups [140] and seems not to correlate with age [108] or disease duration [140].

3.14. Proteomics Research. Recently, a rapid development of proteomic approaches refocused biomarker research interest to the use of novel methods in the discovery of potential MS-specific biomarkers in biological fluids and especially in the CSF $[189,190]$. Among the wide range of proteins that have been found to be exclusively present in the CSF of MS patients [125, 189, 191-194], only some of them are expressed on neurons (contactin-1, neurofascin, neurotrimin, and chromogranins/secretogranins) [193-195]. It was recently shown that contactin-2 was recognised by both autoantibodies and Th1/Th17 T-cells in MS patients $[36,37]$ and neurofascin-specific autoantibodies were identified in MS patients [196]. However, there is a range of neuroaxonal proteins which still need to be studied in CIS/MS patients although some of them have been investigated in animal models [197].

\section{Summary and Future Directives}

Based on the majority of available results, the increased levels of the CSF NF-L or NF-H seem to be present even at early MS phases, a scenario which continues during the entire course of the disease and correlates with different measures of disability; the increased levels of these markers seem to be more pronounced in active disease states and have a potential value in an effort to predict conversion to CDMS after a first CIS episode, estimate future progression and disability, but their value for the prediction of treatment response still has to be investigated, most importantly in early MS patients.

Although the presence of anti-NF antibodies could, in part, be an epiphenomenon of the disease, the elevated levels of these antibodies in progressive disease and correlations with disease duration and disability indicate a rise in antibodies induced by axonal destruction, but also a possible pathogenic role of these antibodies in promoting axonal damage and disease progression. This indicates that serum and/or CSF anti-NF-L, NF-M, and NF-H antibodies might be a potential a marker of CNS tissue damage in MS, but their potential predictive value for the future disease course, disability, disease progression, and treatment response needs to be investigated.

CSF levels of actin and tubulin seem to be elevated in progressive MS and correlate with disability, but their levels in early MS patients, as well as the potential predictive value have been underreported to date.

It is possible that elevated CSF t-tau levels are present from early MS phases and increase in clinically/MRI active disease phases; although its potential correlation with ongoing disease progression has been indicated, the reports related to this molecule so far have been quite contradictory and its validity as a biomarker needs to be further studied both in blood and CSF.

CSF and blood levels of APP-derived proteins seem not to be reliable markers of disease activity or progression since their levels are largely dependent on complex regulatory metabolic processes which could be highly variable in a complex and heterogenous disease such as MS.

A correlation of CSF NAA levels with disability measures even in CIS patients suggests the potential clinical relevance of this molecule as a biomarker that should be further investigated.

NSE and Apo-E levels in CSF/blood are not consistently abnormal in MS patients and their relation to neuroaxonal damage is complicated since the expression of both molecules is not limited to neurons.

CSF/blood levels of GAP-43 were investigated to date in a paucity of studies and some preliminary results might indicate the need for further investigations of this molecule as of the potential biomarker of disease progression and disability.

Serum 24S-OH-chol levels seem to be as reliable as levels in CSF to estimate neuronal membrane status. Some reports indicated its correlation with disability and MS disease activity and thus the validity of this molecule as a biomarker should be further investigated. 
The 14-3-3 family proteins could be potentially related to CIS conversion to MS, disability, and its progression, but this still has to be further confirmed. Astrocyte-derived 143-3 protein could complicate the relation of CSF/blood levels of 14-3-3 protein only to neuroaxonal status in MS.

Additionally, it would be desirable to systematically compare the proteome profiles of MS subgroups at a defined disease stages and in large cohorts in order to identify proteins which are consistently present in the CSF at a certain disease phase in a given subgroup, a task which is still facing a lot of obstacles.

So far, the abovementioned markers have been investigated in the light of their significance to reflect the presence and the extent of neuroaxonal damage in CIS/MS patients. Since each of them could be related to different structural levels of neuroaxonal loss of integrity, the combined evaluation of these markers could be more informative on the ongoing neurodegenerative process [54]. Moreover, the relevance of the single biomarker has to be judged in the light of disease stage and/or disease activity since biomarker levels could show temporal dynamics that correlates with the dynamics of the MS natural course $[54,198]$.

The results of the biomarker studies could have been influenced by small study sizes, cross-sectional designs, and insufficient followup to allow meaningful conclusions [199]. Biomarker studies in MS neurodegeneration have been conducted in a variable patient population, varying from a few [68] to over a hundred patients included [108, 171]. Moreover, followup in most of these studies was up to three years $[54,62,113,140,175,176]$ which could allow only tentative conclusions on biomarker's long-term prognostic significance. The differences in preanalytical processes and different assay sensitivities could also cause contradictory results in biomarker studies [199]. The comparable results were shown in several studies that used the same NF-H Enzyme-Linked Immunosorbent Assay (ELISA) method [62, 70-72]. However, a poor interlaboratory coefficient of variation in a recent multicenter NF-L ELISA validation study has been shown, mainly due to the lack of preparation of accurate and consistent protein standards [200]. Therefore, a standardization of body fluid sampling and storage [201], as well as the use of the standardized and validated assay procedures $[23,200]$, are needed.

Since none of the potential CSF/blood biomarkers studied so far fulfils all necessary criteria for a surrogate biomarker [22] there is an ongoing need for further biomarker studies, especially those aiming to predict future disease course, disability, and/or treatment response at the early MS stage.

\section{Conflict of Interests}

There is no conflict of interests to declare.

\section{Acknowledgment}

This work was supported by a Grant from the Ministry of Science and Technological Development of the Republic of Serbia (Grant no. 175031).

\section{References}

[1] F. Barkhof, P. A. Calabresi, D. H. Miller, and S. C. Reingold, "Imaging outcomes for neuroprotection and repair in multiple sclerosis trials," Nature Reviews Neurology, vol. 5, no. 5, pp. 256-266, 2009.

[2] E. M. Frohman, M. Filippi, O. Stuve et al., "Characterizing the mechanisms of progression in multiple sclerosis: evidence and new hypotheses for future directions," Archives of Neurology, vol. 62, no. 9, pp. 1345-1356, 2005.

[3] J. M. Charcot, Lecons sur les maladies du systeme nerveux faites a la Salpetriere, A. Delahaye, Paris, France, 1880.

[4] N. A. Losseff, S. L. Webb, J. I. O'Riordan et al., "Spinal cord atrophy and disability in multiple sclerosis. A new reproducible and sensitive MRI method with potential to monitor disease progression," Brain, vol. 119, no. 3, pp. 701708, 1996.

[5] N. A. Losseff, L. Wang, H. M. Lai et al., "Progressive cerebral atrophy in multiple sclerosis. A serial MRI study," Brain, vol. 119, no. 6, pp. 2009-2019, 1996.

[6] B. D. Trapp, J. Peterson, R. M. Ransohoff, R. Rudick, S. Mörk, and L. Bö, "Axonal transection in the lesions of multiple sclerosis," New England Journal of Medicine, vol. 338, no. 5, pp. 278-285, 1998.

[7] B. D. Trapp, R. Ransohoff, and R. Rudick, "Axonal pathology in multiple sclerosis: relationship to neurologic disability," Current Opinion in Neurology, vol. 12, no. 3, pp. 295-302, 1999.

[8] C. Bjartmar, G. Kidd, S. Mörk, R. Rudick, and B. D. Trapp, "Neurological disability correlates with spinal cord axonal loss and reduced $\mathrm{N}$-acetyl aspartate in chronic multiple sclerosis patients," Annals of Neurology, vol. 48, no. 6, pp. 893-901, 2000.

[9] B. D. Trapp and K. A. Nave, "Multiple sclerosis: an immune or neurodegenerative disorder?" Annual Review of Neuroscience, vol. 31, pp. 247-269, 2008.

[10] B. Ferguson, M. K. Matyszak, M. M. Esiri, and V. H. Perry, "Axonal damage in acute multiple sclerosis lesions," Brain, vol. 120, no. 3, pp. 393-399, 1997.

[11] J. W. Peterson, L. Bö, S. Mörk, A. Chang, and B. D. Trapp, "Transected neurites, apoptotic neurons, and reduced inflammation in cortical multiple sclerosis lesions," Annals of Neurology, vol. 50, no. 3, pp. 389-400, 2001.

[12] R. Huizinga, W. Gerritsen, N. Heijmans, and S. Amor, "Axonal loss and gray matter pathology as a direct result of autoimmunity to neurofilaments," Neurobiology of Disease, vol. 32, no. 3, pp. 461-470, 2008.

[13] M. Vercellino, S. Masera, M. Lorenzatti et al., "Demyelination, inflammation, and neurodegeneration in multiple sclerosis deep gray matter," Journal of Neuropathology and Experimental Neurology, vol. 68, no. 5, pp. 489-502, 2009.

[14] D. H. Miller, A. J. Thompson, and M. Filippi, "Magnetic resonance studies of abnormalities in the normal appearing white matter and grey matter in multiple sclerosis," Journal of Neurology, vol. 250, no. 12, pp. 1407-1419, 2003.

[15] A. Ceccarelli, M. A. Rocca, A. Falini et al., "Normalappearing white and grey matter damage in MS: a volumetric and diffusion tensor MRI study at 3.0 Tesla," Journal of Neurology, vol. 254, no. 4, pp. 513-518, 2007.

[16] F. Aboul-Enein, M. Krššák, R. Höftberger, D. Prayer, and W. Kristoferitsch, "Reduced NAA-Levels in the NAWM of patients with MS is a feature of progression. A study with quantitative magnetic resonance spectroscopy at 3 Tesla," PLoS ONE, vol. 5, no. 7, article e11625, 2010. 
[17] C. Bjartmar and B. D. Trapp, "Axonal and neuronal degeneration in multiple sclerosis: mechanisms and functional consequences," Current Opinion in Neurology, vol. 14, no. 3, pp. 271-278, 2001.

[18] C. Bjartmar, J. R. Wujek, and B. D. Trapp, "Axonal loss in the pathology of MS: consequences for understanding the progressive phase of the disease," Journal of the Neurological Sciences, vol. 206, no. 2, pp. 165-171, 2003.

[19] R. Dutta and B. D. Trapp, "Pathogenesis of axonal and neuronal damage in multiple sclerosis," Neurology, vol. 68, no. 22, supplement, pp. S22-S31, 2007.

[20] G. Giovannoni, A. J. E. Green, and E. J. Thompson, "Are there any body fluid markers of brain atrophy in multiple sclerosis?" Multiple Sclerosis, vol. 4, no. 3, pp. 138-142, 1998.

[21] C. E. Teunissen, P. C. Dijkstra, and C. Polman, "Biological markers in CSF and blood for axonal degeneration in multiple sclerosis," Lancet Neurology, vol. 4, no. 1, pp. 32-41, 2005.

[22] B. Bielekova and R. Martin, "Development of biomarkers in multiple sclerosis," Brain, vol. 127, no. 7, pp. 1463-1478, 2004.

[23] J. Kuhle, A. Regeniter, D. Leppert et al., "A highly sensitive electrochemiluminescence immunoassay for the neurofilament heavy chain protein," Journal of Neuroimmunology, vol. 220, no. 1-2, pp. 114-119, 2010.

[24] A. Van der Walt, H. Butzkueven, S. Kolbe et al., "Neuroprotection in multiple sclerosis: a therapeutic challenge for the next decade," Pharmacology and Therapeutics, vol. 126, no. 1, pp. 82-93, 2010.

[25] J. Brettschneider, A. Petzold, A. Junker, and H. Tumani, "Axonal damage markers in the cerebrospinal fluid of patients with clinically isolated syndrome improve predicting conversion to definite multiple sclerosis," Multiple Sclerosis, vol. 12, no. 2, pp. 143-148, 2006.

[26] A. Lutterotti, T. Berger, and M. Reindl, "Biological markers for multiple sclerosis," Current Medicinal Chemistry, vol. 14, no. 18, pp. 1956-1965, 2007.

[27] M. Comabella, M. Fernández, R. Martin et al., "Cerebrospinal fluid chitinase 3-like 1 levels are associated with conversion to multiple sclerosis," Brain, vol. 133, no. 4, pp. 1082-1093, 2010.

[28] J. L. Jones and A. J. Coles, "Campath-1H treatment of multiple sclerosis," Neurodegenerative Diseases, vol. 5, no. 1, pp. 27-31, 2007.

[29] H. Wiendl and R. Hohlfeld, "Multiple sclerosis therapeutics: unexpected outcomes clouding undisputed successes," Neurology, vol. 72, no. 11, pp. 1008-1015, 2009.

[30] E. Leray, J. Yaouanq, E. Le Page et al., "Evidence for a twostage disability progression in multiple sclerosis," Brain, vol. 133, no. 7, pp. 1900-1913, 2010.

[31] M. Daumer, A. Neuhaus, S. Morrissey, R. Hintzen, and G. C. Ebers, "MRI as an outcome in multiple sclerosis clinical trials," Neurology, vol. 72, no. 8, pp. 705-711, 2009.

[32] L. Bø, C. A. Vedeler, H. Nyland, B. D. Trapp, and S. J. Mørk, "Intracortical multiple sclerosis lesions are not associated with increased lymphocyte infiltration," Multiple Sclerosis, vol. 9, no. 4, pp. 323-331, 2003.

[33] J. M. Frischer, S. Bramow, A. Dal-Bianco et al., "The relation between inflammation and neurodegeneration in multiple sclerosis brains," Brain, vol. 132, no. 5, pp. 1175-1189, 2009.

[34] H. Lassmann, "What drives disease in multiple sclerosis: inflammation or neurodegeneration?" Clinical and Experimental Neuroimmunology, vol. 1, pp. 2-11, 2010.
[35] E. Silber and M. K. Sharief, "Axonal degeneration in the pathogenesis of multiple sclerosis," Journal of the Neurological Sciences, vol. 170, no. 1, pp. 11-18, 1999.

[36] T. Derfuss, K. Parikh, S. Velhin et al., "Contactin-2/TAG1-directed autoimmunity is identified in multiple sclerosis patients and mediates gray matter pathology in animals," Proceedings of the National Academy of Sciences of the United States of America, vol. 106, no. 20, pp. 8302-8307, 2009.

[37] T. Derfuss, C. Linington, R. Hohlfeld, and E. Meinl, "Axoglial antigens as targets in multiple sclerosis: implications for axonal and grey matter injury," Journal of Molecular Medicine, vol. 88, no. 8, pp. 753-761, 2010.

[38] H. Neumann, I. M. Medana, J. Bauer, and H. Lassmann, "Cytotoxic T lymphocytes in autoimmune and degenerative CNS diseases," Trends in Neurosciences, vol. 25, no. 6, pp. 313319, 2002.

[39] L. H. Kasper and J. Shoemaker, "Multiple sclerosis immunology: the healthy immune system vs the MS immune system," Neurology, vol. 74, pp. S2-S8, 2010.

[40] K. Kierdorf, Y. Wang, and H. Neumann, "Immune-mediated CNS damage," Results and Problems in Cell Differentiation, vol. 51, pp. 173-196, 2010.

[41] D. O. Willenborg, M. A. Staykova, and W. B. Cowden, "Our shifting understanding of the role of nitric oxide in autoimmune encephalomyelitis: a review," Journal of Neuroimmunology, vol. 100, no. 1-2, pp. 21-35, 1999.

[42] G. C. Brown and V. Borutaite, "Nitric oxide inhibition of mitochondrial respiration and its role in cell death," Free Radical Biology and Medicine, vol. 33, no. 11, pp. 1440-1450, 2002.

[43] R. E. Gonsette, "Neurodegeneration in multiple sclerosis: the role of oxidative stress and excitotoxicity," Journal of the Neurological Sciences, vol. 274, no. 1-2, pp. 48-53, 2008.

[44] P. Werner, D. Pitt, and C. S. Raine, "Glutamate excitotoxicity-a mechanism for axonal damage and oligodendrocyte death in multiple sclerosis?" Journal of Neural Transmission, no. 60, pp. 375-385, 2000.

[45] G. Lazzarino, A. M. Amorini, M. J. Eikelenboom et al., "Cerebrospinal fluid ATP metabolites in multiple sclerosis," Multiple Sclerosis, vol. 16, no. 5, pp. 549-554, 2010.

[46] D. Mahad, H. Lassmann, and D. Turnbull, "Review: mitochondria and disease progression in multiple sclerosis," Neuropathology and Applied Neurobiology, vol. 34, no. 6, pp. 577589, 2008.

[47] T. Owens, "The enigma of multiple sclerosis: inflammation and neurodegeneration cause heterogeneous dysfunction and damage," Current Opinion in Neurology, vol. 16, no. 3, pp. 259-265, 2003.

[48] S. G. Waxman, M. J. Craner, and J. A. Black, "Na+ channel expression along axons in multiple sclerosis and its models," Trends in Pharmacological Sciences, vol. 25, no. 11, pp. 584591, 2004.

[49] M. N. Rasband, J. Tayler, Y. Kaga et al., "CNP is required for maintenance of axon-glia interactions at nodes of ranvier in the CNS," GLIA, vol. 50, no. 1, pp. 86-90, 2005.

[50] O. W. Howell, J. L. Rundle, A. Garg, M. Komada, P. J. Brophy, and R. Reynolds, "Activated microglia mediate axoglial disruption that contributes to axonal injury in multiple sclerosis," Journal of Neuropathology and Experimental Neurology, vol. 69, no. 10, pp. 1017-1033, 2010.

[51] S. Petratos, M. F. Azari, E. Ozturk, R. Papadopoulos, and C. C. A. Bernard, "Novel therapeutic targets for axonal degeneration in multiple sclerosis," Journal of Neuropathology 
and Experimental Neurology, vol. 69, no. 4, pp. 323-334, 2010.

[52] Y. Yang, Y. Liu, P. Wei et al., "Silencing Nogo-a promotes functional recovery in demyelinating disease," Annals of Neurology, vol. 67, no. 4, pp. 498-507, 2010.

[53] P. Spitzer, H. W. Klafki, K. Blennow et al., "CNEUPRO: novel biomarkers for neurodegenerative diseases," International Journal of Alzheimer's Disease, vol. 2010, Article ID 548145, 12 pages, 2010.

[54] C. E. Teunissen, E. Iacobaeus, M. Khademi et al., "Combination of CSF N-acetylaspartate and neurofilaments in multiple sclerosis," Neurology, vol. 72, no. 15, pp. 1322-1329, 2009.

[55] M. K. Lee and D. W. Cleveland, "Neuronal intermediate filaments," Annual Review of Neuroscience, vol. 19, pp. 187217, 1996.

[56] M. M. Gresle, G. Shaw, B. Jarrott et al., "Validation of a novel biomarker for acute axonal injury in experimental autoimmune encephalomyelitis," Journal of Neuroscience Research, vol. 86, no. 16, pp. 3548-3555, 2008.

[57] A. Petzold, "Neurofilament phosphoforms: surrogate markers for axonal injury, degeneration and loss," Journal of the Neurological Sciences, vol. 233, no. 1-2, pp. 183-198, 2005.

[58] M. E. Goldstein, N. H. Sternberger, and L. A. Sternberger, "Phosphorylation protects neurofilaments against proteolysis," Journal of Neuroimmunology, vol. 14, no. 2, pp. 149-160, 1987.

[59] J. P. Julien and W. E. Mushynski, "Neurofilaments in health and disease," Progress in Nucleic Acid Research and Molecular Biology, vol. 61, pp. 1-23, 1998.

[60] E. Fuchs and D. W. Cleveland, "A structural scaffolding of intermediate filaments in health and disease," Science, vol. 279, no. 5350, pp. 514-519, 1998.

[61] J. N. Lycke, J. E. Karlsson, O. Andersen, and L. E. Rosengren, "Neurofilament protein in cerebrospinal fluid: a potential marker of activity in multiple sclerosis," Journal of Neurology Neurosurgery and Psychiatry, vol. 64, no. 3, pp. 402-404, 1998.

[62] A. Petzold, M. J. Eikelenboom, G. Keir et al., "Axonal damage accumulates in the progressive phase of multiple sclerosis: three year follow up study," Journal of Neurology, Neurosurgery and Psychiatry, vol. 76, no. 2, pp. 206-211, 2005.

[63] Y. K. Semra, O. A. Seidi, and M. K. Sharief, "Heightened intrathecal release of axonal cytoskeletal proteins in multiple sclerosis is associated with progressive disease and clinical disability," Journal of Neuroimmunology, vol. 122, no. 1-2, pp. 132-139, 2002.

[64] C. Malmeström, S. Haghighi, L. Rosengren, O. Andersen, and J. Lycke, "Neurofilament light protein and glial fibrillary acidic protein as biological markers in MS," Neurology, vol. 61, no. 12, pp. 1720-1725, 2003.

[65] N. Norgren, P. Sundström, A. Svenningsson, L. Rosengren, T. Stigbrand, and M. Gunnarsson, "Neurofilament and glial fibrillary acidic protein in multiple sclerosis," Neurology, vol. 63, no. 9, pp. 1586-1590, 2004.

[66] M. J. Eikelenboom, A. Petzold, R. H. C. Lazeron et al., "Multiple sclerosis: neurofilament light chain antibodies are correlated to cerebral atrophy," Neurology, vol. 60, no. 2, pp. 219-223, 2003.

[67] S. Haghighi, O. Andersen, A. Odén, and L. Rosengren, "Cerebrospinal fluid markers in MS patients and their healthy siblings," Acta Neurologica Scandinavica, vol. 109, no. 2, pp. 97-99, 2004.

[68] L. E. Rosengren, J. E. Karlsson, J. O. Karlsson, L. I. Persson, and C. Wikkelsø, "Patients with amyotrophic lateral sclerosis and other neurodegenerative diseases have increased levels of neurofilament protein in CSF," Journal of Neurochemistry, vol. 67, no. 5, pp. 2013-2018, 1996.

[69] E. T. Lim, D. Grant, M. Pashenkov et al., "Cerebrospinal fluid levels of brain specific proteins in optic neuritis," Multiple Sclerosis, vol. 10, no. 3, pp. 261-265, 2004.

[70] I. Miyazawa, I. Nakashima, A. Petzold, K. Fujihara, S. Sato, and Y. Itoyama, "High CSF neurofilament heavy chain levels in neuromyelitis optica," Neurology, vol. 68, no. 11, pp. 865867, 2007.

[71] A. Petzold, K. Rejdak, and G. T. Plant, "Axonal degenaration and inflammation in acute optic neuritis," Journal of Neurology, Neurosurgery and Psychiatry, vol. 75, no. 8, pp. 11781180, 2004.

[72] K. Rejdak, A. Petzold, Z. Stelmasiak, and G. Giovannoni, "Cerebrospinal fluid brain specific proteins in relation to nitric oxide metabolites during relapse of multiple sclerosis," Multiple Sclerosis, vol. 14, no. 1, pp. 59-66, 2008.

[73] N. Norgren, L. Rosengren, and T. Stigbrand, "Elevated neurofilament levels in neurological diseases," Brain Research, vol. 987, no. 1, pp. 25-31, 2003.

[74] E. Silber, Y. K. Semra, N. A. Gregson, and M. K. Sharief, "Patients with progressive multiple sclerosis have elevated antibodies to neurofilament subunit," Neurology, vol. 58, no. 9, pp. 1372-1381, 2002.

[75] J. Salzer, A. Svenningsson, and P. Sundström, "Neurofilament light as a prognostic marker in multiple sclerosis," Multiple Sclerosis, vol. 16, no. 3, pp. 287-292, 2010.

[76] A. Petzold, M. J. Eikelenboom, G. Keir et al., "The new global multiple sclerosis severity score (MSSS) correlates with axonal but not glial biomarkers," Multiple Sclerosis, vol. 12, no. 3, pp. 325-328, 2006.

[77] A. Petzold, D. Brassat, P. Mas et al., "Treatment response in relation to inflammatory and axonal surrogate marker in multiple sclerosis," Multiple Sclerosis, vol. 10, no. 3, pp. 281283, 2004.

[78] E. T. Lim, F. Sellebjerg, C. V. Jensen et al., "Acute axonal damage predicts clinical outcome in patients with multiple sclerosis," Multiple Sclerosis, vol. 11, no. 5, pp. 532-536, 2005.

[79] A. Bartoš, L. Fialová, J. Soukupová, J. Kukal, I. Malbohan, and J. Pitha, "Antibodies against light neurofilaments in multiple sclerosis patients," Acta Neurologica Scandinavica, vol. 116, no. 2, pp. 100-107, 2007.

[80] R. Ehling, A. Lutterotti, J. Wanschitz et al., "Increased frequencies of serum antibodies to neurofilament light in patients with primary chronic progressive multiple sclerosis," Multiple Sclerosis, vol. 10, no. 6, pp. 601-606, 2004.

[81] L. Fialová, A. Bartoš, J. Soukupová, J. Švarcová, P. Ridzoň, and I. Malbohan, "Synergy of serum and cerebrospinal fluid antibodies against axonal cytoskeletal proteins in patients with different neurological diseases," Folia Biologica, vol. 55, no. 1, pp. 23-26, 2009.

[82] A. Bartoš, L. Fialová, J. Soukupová, J. Kukal, I. Malbohan, and J. Pit'ha, "Elevated intrathecal antibodies against the medium neurofilament subunit in multiple sclerosis," Journal of Neurology, vol. 254, no. 1, pp. 20-25, 2007.

[83] J. Švarcová, L. Fialová, A. Bartoš, M. Šteinbachová, and I. Malbohan, "Cerebrospinal fluid antibodies to tubulin are elevated in the patients with multiple sclerosis," European Journal of Neurology, vol. 15, no. 11, pp. 1173-1179, 2008.

[84] F. Forooghian, R. K. Cheung, W. C. Smith, P. O'Connor, and H. M. Dosch, "Enolase and arrestin are novel nonmyelin autoantigens in multiple sclerosis," Journal of Clinical Immunology, vol. 27, no. 4, pp. 388-396, 2007. 
[85] D. B. Braxton, M. Williams, D. Kamali, S. Chin, R. Liem, and N. Latov, "Specificity of human anti-neurofilament autoantibodies," Journal of Neuroimmunology, vol. 21, no. 23, pp. 193-203, 1989.

[86] B. O. Fabriek, J. N. P. Zwemmer, C. E. Teunissen et al., "In vivo detection of myelin proteins in cervical lymph nodes of MS patients using ultrasound-guided fine-needle aspiration cytology," Journal of Neuroimmunology, vol. 161, no. 1-2, pp. 190-194, 2005.

[87] A. Prat and J. Antel, "Pathogenesis of multiple sclerosis," Current Opinion in Neurology, vol. 18, no. 3, pp. 225-230, 2005.

[88] K. Kamath, E. Oroudjev, and M. A. Jordan, "Determination of microtubule dynamic instability in living cells," Methods in Cell Biology, vol. 97, pp. 1-14, 2010.

[89] K. H. Downing, "Structural basis for the interaction of tubulin with proteins and drugs that affect microtubule dynamics," Annual Review of Cell and Developmental Biology, vol. 16, pp. 89-111, 2000.

[90] N. B. Laferrière, T. H. MacRae, and D. L. Brown, "Tubulin synthesis and assembly in differentiating neurons," Biochemistry and Cell Biology, vol. 75, no. 2, pp. 103-117, 1997.

[91] D. Girard and J. L. Senécal, "Anti-microfilament IgG antibodies in normal adults and in patients with autoimmune diseases: immunofluorescence and immunoblotting analysis of 201 subjects reveals polyreactivity with microfilament-associated proteins," Clinical Immunology and Immunopathology, vol. 74, no. 2, pp. 193-201, 1995.

[92] A. Kulakowska, W. Drozdowski, A. Sadzynski, R. Bucki, and P. A. Janmey, "Gelsolin concentration in cerebrospinal fluid from patients with multiple sclerosis and other neurological disorders," European Journal of Neurology, vol. 15, no. 6, pp. 584-588, 2008.

[93] T. Paunio, H. Kangash, O. Heinonen et al., "Cells of the neuronal lineage play a major role in the generation of amyloid precursor fragments in gelsolin-related amyloidosis," Journal of Biological Chemistry, vol. 273, no. 26, pp. 16319-16324, 1998.

[94] H. L. Yin, D. J. Kwiatokowski, J. E. Mole, and F. S. Cole, "Structure and biosynthesis of cytoplasmic and secreted variants of gelsolin," Journal of Biological Chemistry, vol. 259, no. 8, pp. 5271-5276, 1984.

[95] W. M. Lee and R. M. Galbraith, "The extracellular actinscavenger system and actin toxicity," New England Journal of Medicine, vol. 326, no. 20, pp. 1335-1341, 1992.

[96] A. Kułakowska, N. J. Ciccarelli, Q. Wen et al., "Hypogelsolinemia, a disorder of the extracellular actin scavenger system, in patients with multiple sclerosis," BMC Neurology, vol. 10, article 107, 2010.

[97] C. Ballatore, V. M. Y. Lee, and J. Q. Trojanowski, "Taumediated neurodegeneration in Alzheimer's disease and related disorders," Nature Reviews Neuroscience, vol. 8, no. 9, pp. 663-672, 2007.

[98] G. V. W. Johnson and W. H. Stoothoff, "Tau phosphorylation in neuronal cell function and dysfunction," Journal of Cell Science, vol. 117, no. 24, pp. 5721-5729, 2004.

[99] B. Bandyopadhyay, G. Li, H. Yin, and J. Kuret, "Tau aggregation and toxicity in a cell culture model of tauopathy," Journal of Biological Chemistry, vol. 282, no. 22, pp. 1645416464, 2007.

[100] J. M. Anderson, R. Patani, R. Reynolds et al., "Evidence for abnormal tau phosphorylation in early aggressive multiple sclerosis," Acta Neuropathologica, vol. 117, no. 5, pp. 583-589, 2009.
[101] J. M. Anderson, D. W. Hampton, R. Patani et al., "Abnormally phosphorylated tau is associated with neuronal and axonal loss in experimental autoimmune encephalomyelitis and multiple sclerosis," Brain, vol. 131, no. 7, pp. 1736-1748, 2008.

[102] J. M. Anderson, R. Patani, R. Reynolds et al., "Abnormal tau phosphorylation in primary progressive multiple sclerosis," Acta Neuropathologica, vol. 119, no. 5, pp. 591-600, 2010.

[103] J. Brettschneider, M. Maier, S. Arda et al., "Tau protein level in cerebrospinal fluid is increased in patients with early multiple sclerosis," Multiple Sclerosis, vol. 11, no. 3, pp. 261265, 2005.

[104] J. Guimarães, M. J. Cardoso, and M. J. Sá, “Tau protein seems not to be a useful routine clinical marker of axonal damage in multiple sclerosis," Multiple Sclerosis, vol. 12, no. 3, pp. 354356, 2006.

[105] K. Hein Née Maier, A. Köhler, R. Diem et al., "Biological markers for axonal degeneration in CSF and blood of patients with the first event indicative for multiple sclerosis," Neuroscience Letters, vol. 436, no. 1, pp. 72-76, 2008.

[106] M. Vališ, R. Taláb, P. Šťourač, C. Andrýs, and J. Masopust, "Tau protein, phosphorylated tau protein and betaamyloid42 in the cerebrospinal fluid of multiple sclerosis patients," Neuroendocrinology Letters, vol. 29, no. 6, pp. 971976, 2008.

[107] E. Kapaki, G. P. Paraskevas, M. Michalopoulou, and K. Kilidireas, "Increased cerebrospinal fluid tau protein in multiple sclerosis," European Neurology, vol. 43, no. 4, pp. 228-232, 2000.

[108] H. Bartosik-Psujek and J. J. Archelos, "Tau protein and 143-3 are elevated in the cerebrospinal fluid of patients with multiple sclerosis and correlate with intrathecal synthesis of IgG," Journal of Neurology, vol. 251, no. 4, pp. 414-420, 2004.

[109] H. Bartosik-Psujek and Z. Stelmasiak, "The CSF levels of total-tau and phosphotau in patients with relapsingremitting multiple sclerosis," Journal of Neural Transmission, vol. 113, no. 3, pp. 339-345, 2006.

[110] M. Terzi, A. Birinci, E. Çetinkaya, and M. K. Onar, "Cerebrospinal fluid total tau protein levels in patients with multiple sclerosis," Acta Neurologica Scandinavica, vol. 115, no. 5, pp. 325-330, 2007.

[111] F. J. Jiménez-Jiménez, J. M. Zurdo, A. Hernanz et al., "Tau protein concentrations in cerebrospinal fluid of patients with multiple sclerosis," Acta Neurologica Scandinavica, vol. 106, no. 6, pp. 351-354, 2002.

[112] K. Rostasy, E. Withut, D. Pohl et al., "Tau, phospho-tau, and S-100B in the cerebrospinal fluid of children with multiple sclerosis," Journal of Child Neurology, vol. 20, no. 10, pp. 822825, 2005.

[113] A. Martínez-Yélamos, A. Saiz, J. Bas, J. J. Hernandez, F. Graus, and T. Arbizu, "Tau protein in cerebrospinal fluid: a possible marker of poor outcome in patients with early relapsing-remitting multiple sclerosis," Neuroscience Letters, vol. 363, no. 1, pp. 14-17, 2004.

[114] S. D. Süssmuth, H. Reiber, and H. Tumani, "Tau protein in cerebrospinal fluid (CSF): a blood-CSF barrier related evaluation in patients with various neurological diseases," Neuroscience Letters, vol. 300, no. 2, pp. 95-98, 2001.

[115] A. Gajofatto, S. Monaco, M. Fiorini et al., "Assessment of outcome predictors in first-episode acute myelitis a retrospective study of 53 cases," Archives of Neurology, vol. 67, no. 6, pp. 724-730, 2010. 
[116] A. Schneider, G. W. Araújo, K. Trajkovic et al., "Hyperphosphorylation and aggregation of tau in experimental autoimmune encephalomyelitis," Journal of Biological Chemistry, vol. 279, no. 53, pp. 55833-55839, 2004.

[117] A. Scheurich, P. P. Urban, N. Koch-Khoury, and A. Fellgiebel, "CSF phospho-tau is independent of age, cognitive status and gender of neurological patients," Journal of Neurology, vol. 257, no. 4, pp. 609-614, 2010.

[118] P. R. Turner, K. O’Connor, W. P. Tate, and W. C. Abraham, "Roles of amyloid precursor protein and its fragments in regulating neural activity, plasticity and memory," Progress in Neurobiology, vol. 70, no. 1, pp. 1-32, 2003.

[119] E. H. Koo, S. S. Sisodia, D. R. Archer et al., "Precursor of amyloid protein in Alzheimer disease undergoes fast anterograde axonal transport," Proceedings of the National Academy of Sciences of the United States of America, vol. 87, no. 4, pp. 1561-1565, 1990.

[120] W. Brück and C. Stadelmann, "Inflammation and degeneration in multiple sclerosis," Neurological Sciences, vol. 24, no. 5, pp. S265-S267, 2003.

[121] J. Gehrmann, R. B. Banati, M. L. Cuzner, G. W. Kreutzberg, and J. Newcombe, "Amyloid precursor protein (APP) expression in multiple sclerosis lesions," Glia, vol. 15, no. 2, pp. 141151, 1995.

[122] N. Mattsson, M. Axelsson, S. Haghighi et al., "Reduced cerebrospinal fluid BACE1 activity in multiple sclerosis," Multiple Sclerosis, vol. 15, no. 4, pp. 448-454, 2009.

[123] U. Andreasson, E. Portelius, M. E. Andersson, K. Blennow, and $\mathrm{H}$. Zetterberg, "Aspects of beta-amyloid as a biomarker for Alzheimer's disease," Biomarkers in Medicine, vol. 1, no. 1, pp. 59-78, 2007.

[124] J. Kim, V. M. Miller, Y. Levites et al., "BRI2 (ITM2b) inhibits $\mathrm{A} \beta$ deposition in vivo," Journal of Neuroscience, vol. 28, no. 23, pp. 6030-6036, 2008.

[125] V. K. Harris, A. Diamanduros, P. Good, E. Zakin, V. Chalivendra, and S. A. Sadiq, "Bri2-23 is a potential cerebrospinal fluid biomarker in multiple sclerosis," Neurobiology of Disease, vol. 40, no. 1, pp. 331-339, 2010.

[126] F. Mori, S. Rossi, G. Sancesario et al., "Cognitive and cortical plasticity deficits correlate with altered amyloid- $\beta$ CSF levels in multiple sclerosis," Neuropsychopharmacology, vol. 36, no. 3, pp. 559-568, 2011.

[127] T. Tokuda, T. Oide, A. Tamaoka, K. Ishii, S. Matsuno, and S. Ikeda, "Prednisolone (30-60 mg/day) for diseases other than $\mathrm{AD}$ decreases amyloid $\beta$-peptides in CSF," Neurology, vol. 58, no. 9, pp. 1415-1418, 2002.

[128] C. Bjartmar, J. Battistuta, N. Terada, E. Dupree, and B. D. Trapp, "N-acetylaspartate is an axon-specific marker of mature white matter in vivo: a biochemical and immunohistochemical study on the rat optic nerve," Annals of Neurology, vol. 51, no. 1, pp. 51-58, 2002.

[129] J. R. Moffett, B. Ross, P. Arun, C. N. Madhavarao, and A. M. A. Namboodiri, "N-Acetylaspartate in the CNS: from neurodiagnostics to neurobiology," Progress in Neurobiology, vol. 81, no. 2, pp. 89-131, 2007.

[130] D. J. Rigotti, M. Inglese, and O. Gonen, "Whole-brain Nacetylaspartate as a surrogate marker of neuronal damage in diffuse neurologic disorders," American Journal of Neuroradiology, vol. 28, no. 10, pp. 1843-1849, 2007.

[131] O. Khan, Y. Shen, C. Caon et al., "Axonal metabolic recovery and potential neuroprotective effect of glatiramer acetate in relapsing-remitting multilple sclerosis," Multiple Sclerosis, vol. 11, no. 6, pp. 646-651, 2005.
[132] M. Tiberio, D. T. Chard, D. R. Altmann et al., "Metabolite changes in early relapsing-remitting multiple sclerosis: a two year follow-up study," Journal of Neurology, vol. 253, no. 2, pp. 224-230, 2006.

[133] D. J. Rigotti, O. Gonen, R. I. Grossman et al., "Global Nacetylaspartate declines even in benign multiple sclerosis," American Journal of Neuroradiology, vol. 32, no. 1, pp. 204209, 2011.

[134] M. Van Au Duong, B. Audoin, Y. Le Fur et al., "Relationships between gray matter metabolic abnormalities and white matter inflammation in patients at the very early stage of MS: a MRSI study," Journal of Neurology, vol. 254, no. 7, pp. 914923, 2007.

[135] K. Viala, J. L. Stievenart, E. A. Cabanis, O. Lyon-Caen, and A. Tourbah, "Study with localized proton magnetic resonance spectroscopy of 31 multiple sclerosis lesions: correlations with clinical and MRI features," Revue Neurologique, vol. 157, no. 1, pp. 35-44, 2001.

[136] N. De Stefano, P. M. Matthews, L. Fu et al., "Axonal damage correlates with disability in patients with relapsing-remitting multiple sclerosis. Results of a longitudinal magnetic resonance spectroscopy study," Brain, vol. 121, no. 8, pp. 14691477, 1998.

[137] N. De Stefano, S. Narayanan, G. S. Francis et al., "Evidence of axonal damage in the early stages of multiple sclerosis and its relevance to disability," Archives of Neurology, vol. 58, no. 1, pp. 65-70, 2001.

[138] N. De Stefano, G. Iannucci, M. P. Sormani et al., "MR correlates of cerebral atrophy in patients with multiple sclerosis," Journal of Neurology, vol. 249, no. 8, pp. 10721077, 2002.

[139] S. Narayanan, N. De Stefano, G. S. Francis et al., "Axonal metabolic recovery in multiple sclerosis patients treated with interferon $\beta$-1b," Journal of Neurology, vol. 248, no. 11, pp. 979-986, 2001.

[140] M. Colucci, L. Roccatagliata, E. Capello et al., "The 14-3-3 protein in multiple sclerosis: a marker of disease severity," Multiple Sclerosis, vol. 10, no. 5, pp. 477-481, 2004.

[141] B. Jasperse, C. Jakobs, M. J. Eikelenboom et al., "Nacetylaspartic acid in cerebrospinal fluid of multiple sclerosis patients determined by gas-chromatography-mass spectrometry," Journal of Neurology, vol. 254, no. 5, pp. 631-637, 2007.

[142] R. T. Cunningham, J. I. Morrow, C. F. Johnston, and K. D. Buchanan, "Serum neurone-specific enolase concentrations in patients with neurological disorders," Clinica Chimica Acta, vol. 230, no. 2, pp. 117-124, 1994.

[143] M. Koch, J. Mostert, D. Heersema, A. Teelken, and J. De Keyser, "Plasma S100 $\beta$ and NSE levels and progression in multiple sclerosis," Journal of the Neurological Sciences, vol. 252, no. 2, pp. 154-158, 2007.

[144] P. J. H. Jongen, K. J. B. Lamers, W. H. Doesburg, W. A. J. G. Lemmens, and O. R. Hommes, "Cerebrospinal fluid analysis differentiates between relapsing-remitting and secondary progressive multiple sclerosis," Journal of Neurology Neurosurgery and Psychiatry, vol. 63, no. 4, pp. 446-451, 1997.

[145] V. I. Zannis, "Genetic polymorphism in human apolipoprotein E," Methods in Enzymology, vol. 128, pp. 823-851, 1986.

[146] H. L. Zhang, J. Wu, and J. Zhu, "The immune-modulatory role of apolipoprotein e with emphasis on multiple sclerosis and experimental autoimmune encephalomyelitis," Clinical and Developmental Immunology, vol. 2010, Article ID 186813, 2010. 
[147] M. Mulder, A. Blokland, D. J. Van Den Berg et al., "Apolipoprotein $\mathrm{E}$ protects against neuropathology induced by a high-fat diet and maintains the integrity of the blood-brain barrier during aging," Laboratory Investigation, vol. 81, no. 7, pp. 953-960, 2001.

[148] B. B. Gelman, N. Rifai, R. H. Christenson, and L. M. Silverman, "Cerebrospinal fluid and plasma apolipoproteins in patients with multiple sclerosis," Annals of Clinical and Laboratory Science, vol. 18, no. 1, pp. 46-52, 1988.

[149] J. Carlsson, V. W. Armstrong, H. Reiber, K. Felgenhauer, and D. Seidel, "Clinical relevance of the quantification of apolipoprotein E in cerebrospinal fluid," Clinica Chimica Acta, vol. 196, no. 2-3, pp. 167-176, 1991.

[150] P. Hogh, A. Oturai, K. Schreiber et al., "Apoliprotein E and multiple sclerosis: impact of the epsilon-4 allele on susceptibility, clinical type and progression rate," Multiple Sclerosis, vol. 6, no. 4, pp. 226-230, 2000.

[151] N. De Stefano, M. L. Bartolozzi, B. Nacmias et al., "Influence of apolipoprotein E $\varepsilon 4$ genotype on brain tissue integrity in relapsing-remitting multiple sclerosis," Archives of Neurology, vol. 61, no. 4, pp. 536-540, 2004.

[152] E. Portaccio, V. Zipoli, B. Goretti et al., "ApolipoproteinE epsilon 4 allele is not associated with disease course and severity in multiple sclerosis," Acta Neurologica Scandinavica, vol. 120, no. 6, pp. 439-441, 2009.

[153] F. Fazekas, S. Strasser-Fuchs, H. Kollegger et al., "Apolipoprotein $\mathrm{E} \varepsilon 4$ is associated with rapid progression of multiple sclerosis," Neurology, vol. 57, no. 5, pp. 853-857, 2001.

[154] M. Pinholt, J. L. Frederiksen, P. S. Andersen, and M. Christiansen, "Apo E in multiple sclerosis and optic neuritis: the Apo E- $\varepsilon 4$ allele is associated with progression of multiple sclerosis," Multiple Sclerosis, vol. 11, no. 5, pp. 511-515, 2005.

[155] C. Enzinger, S. Ropele, S. Strasser-Fuchs et al., "Lower levels of N-acetylaspartate in multiple sclerosis patients with the apolipoprotein E $\varepsilon 4$ allele," Archives of Neurology, vol. 60, no. 1, pp. 65-70, 2003.

[156] A. Sena, R. Couderc, V. Ferret-Sena et al., "Apolipoprotein e polymorphism interacts with cigarette smoking in progression of multiple sclerosis," European Journal of Neurology, vol. 16, no. 7, pp. 832-837, 2009.

[157] J. Shi, C. B. Zhao, T. L. Vollmer, T. M. Tyry, and S. M. Kuniyoshi, "APOE $\varepsilon 4$ allele is associated with cognitive impairment in patients with multiple sclerosis," Neurology, vol. 70, no. 3, pp. 185-190, 2008.

[158] E. Portaccio, B. Goretti, V. Zipoli et al., "APOE- $\varepsilon 4$ is not associated with cognitive impairment in relapsingremitting multiple sclerosis," Multiple Sclerosis, vol. 15, no. 12, pp. 1489-1494, 2009.

[159] O. Gaillard, A. Gervais, D. Meillet et al., "Apolipoprotein E and multiple sclerosis: a biochemical and genetic investigation," Journal of the Neurological Sciences, vol. 158, no. 2, pp. 180-186, 1998.

[160] N. Rifai, R. H. Christenson, B. B. Gelman, and L. M. Silverman, "Changes in cerebrospinal fluid IgG and apolipoprotein $\mathrm{E}$ indices in patients with multiple sclerosis during demyelination and remyelination," Clinical Chemistry, vol. 33, no. 7, pp. 1155-1157, 1987.

[161] D. Chiasserini, M. Di Filippo, A. Candeliere et al., "CSF proteome analysis in multiple sclerosis patients by twodimensional electrophoresis," European Journal of Neurology, vol. 15, no. 9, pp. 998-1001, 2008.

[162] G. Giovannoni, "Multiple sclerosis cerebrospinal fluid biomarkers," Disease Markers, vol. 22, no. 4, pp. 187-196, 2006.
[163] V. Hoffmann, W. Kuhn, S. Schimrigk et al., "Repeat intrathecal triamcinolone acetonide application is beneficial in progressive MS patients," European Journal of Neurology, vol. 13, no. 1, pp. 72-76, 2006.

[164] B. G. M. Van Engelen, K. J. B. Lamers, F. J. M. Gabreels, R. A. Wevers, W. J. A. Van Geel, and G. F. Borm, "Agerelated changes of neuron-specific enolase, S-100 protein, and myelin basic protein concentrations in cerebrospinal fluid," Clinical Chemistry, vol. 38, no. 6, pp. 813-816, 1992.

[165] J. Finsterer, M. Exner, and H. Rumpold, "Cerebrospinal fluid neuron-specific enolase in non-selected patients," Scandinavian Journal of Clinical and Laboratory Investigation, vol. 64, no. 6, pp. 553-558, 2004.

[166] A. B. Oestreicher, P. N. E. De Graan, W. H. Gispen, J. Verhaagen, and L. H. Schrama, "B-50, the growth associated protein-43: modulation of cell morphology and communication in the nervous system," Progress in Neurobiology, vol. 53, no. 6, pp. 627-686, 1997.

[167] C. E. Teunissen, C. D. Dijkstra, B. Jasperse et al., "Growthassociated protein 43 in lesions and cerebrospinal fluid in multiple sclerosis," Neuropathology and Applied Neurobiology, vol. 32, no. 3, pp. 318-331, 2006.

[168] V. Leoni, "Oxysterols as markers of neurological diseasea review," Scandinavian Journal of Clinical and Laboratory Investigation, vol. 69, no. 1, pp. 22-25, 2009.

[169] V. D. Karrenbauer, V. Leoni, EE. T. Lim et al., "Plasma cerebrosterol and magnetic resonance imaging measures in multiple sclerosis," Clinical Neurology and Neurosurgery, vol. 108, no. 5, pp. 456-460, 2006.

[170] L. Bretillon, Å. Sidén, L. O. Wahlund et al., "Plasma levels of 24S-hydroxycholesterol in patients with neurological diseases," Neuroscience Letters, vol. 293, no. 2, pp. 87-90, 2000.

[171] V. Leoni, T. Masterman, U. Diczfalusy, G. De Luca, J. Hillert, and I. Björkhem, "Changes in human plasma levels of the brain specific oxysterol 24S-hydroxycholesterol during progression of multiple sclerosis," Neuroscience Letters, vol. 331, no. 3, pp. 163-166, 2002.

[172] C. E. Teunissen, C. D. Dijkstra, C. H. Polman, E. L. J. Hoogervorst, K. Von Bergmann, and D. Lütjohann, "Decreased levels of the brain specific 24S-hydroxycholesterol and cholesterol precursors in serum of multiple sclerosis patients," Neuroscience Letters, vol. 347, no. 3, pp. 159-162, 2003.

[173] V. Leoni, T. Masterman, F. S. Mousavi et al., "Diagnostic use of cerebral and extracerebral oxysterols," Clinical Chemistry and Laboratory Medicine, vol. 42, no. 2, pp. 186-191, 2004.

[174] J. De Seze, K. Peoc'h, D. Ferriby, T. Stojkovic, J. L. Laplanche, and P. Vermersch, "14-3-3 Protein in the cerebrospinal fluid of patients with acute transverse myelitis and multiple sclerosis," Journal of Neurology, vol. 249, no. 5, pp. 626-627, 2002.

[175] A. Martínez-Yélamos, A. Saiz, R. Sanchez-Valle et al., "14-33 Protein in the CSF as prognostic marker in early multiple sclerosis," Neurology, vol. 57, no. 4, pp. 722-724, 2001.

[176] A. Martínez-Yélamos, A. Rovira, R. Sánchez-Valle et al., "CSF 14-3-3 protein assay and MRI as prognostic markers in patients with a clinically isolated syndrome suggestive of MS," Journal of Neurology, vol. 251, no. 10, pp. 1278-1279, 2004.

[177] L. Bretillon, D. Lütjohann, L. Ståhle et al., "Plasma levels of 24S-hydroxycholesterol reflect the balance between cerebral production and hepatic metabolism and are inversely related to body surface," Journal of Lipid Research, vol. 41, no. 5, pp. 840-845, 2000. 
[178] I. Björkhem, S. Meaney, and A. M. Fogelman, "Brain cholesterol: long secret life behind a barrier," Arteriosclerosis, Thrombosis, and Vascular Biology, vol. 24, no. 5, pp. 806-815, 2004.

[179] V. Leoni, T. Masterman, P. Patel, S. Meaney, U. Diczfalusy, and I. Björkhem, "Side chain oxidized oxysterols in cerebrospinal fluid and the integrity of blood-brain and bloodcerebrospinal fluid barriers," Journal of Lipid Research, vol. 44, no. 4, pp. 793-799, 2003.

[180] P. F. Boston, P. Jackson, and R. J. Thompson, "Human 14-33 protein: radioimmunoassay, tissue distribution, and cerebrospinal fluid levels in patients with neurological disorders," Journal of Neurochemistry, vol. 38, no. 5, pp. 1475-1482, 1982.

[181] J. I. Satoh, K. Kurohara, M. Yukitake, and Y. Kuroda, “The 143-3 protein detectable in the cerebrospinal fluid of patients with prion-unrelated neurological diseases is expressed constitutively in neurons and glial cells in culture," European Neurology, vol. 41, no. 4, pp. 216-225, 1999.

[182] J.-I. Satoh, T. Yamamura, and K. Arima, "The 14-3-3 protein $\varepsilon$ isoform expressed in reactive astrocytes in demyelinating lesions of multiple sclerosis binds to vimentin and glial fibrillary acidic protein in cultured human astrocytes," American Journal of Pathology, vol. 165, no. 2, pp. 577-592, 2004.

[183] H. Slaets, D. Dumont, J. Vanderlocht et al., "Leukemia inhibitory factor induces an antiapoptotic response in oligodendrocytes through Akt-phosphorylation and upregulation of 14-3-3," Proteomics, vol. 8, no. 6, pp. 1237-1247, 2008.

[184] J. M. Woodcock, Y. Ma, C. Coolen et al., "Sphingosine and FTY720 directly bind pro-survival 14-3-3 proteins to regulate their function," Cellular Signalling, vol. 22, no. 9, pp. 12911299, 2010.

[185] F. Deisenhammer, R. Egg, G. Giovannoni et al., "EFNS guidelines on disease-specific CSF investigations," European Journal of Neurology, vol. 16, no. 6, pp. 760-770, 2009.

[186] A. Saiz, F. Graus, J. Dalmau, A. Pifarré, C. Marín, and E. Tolosa, "Detection of 14-3-3 brain protein in the cerebrospinal fluid of patients with paraneoplastic neurological disorders," Annals of Neurology, vol. 46, no. 5, pp. 774-777, 1999.

[187] J. I. Satoh, M. Yukitake, K. Kurohara, H. Takashima, and Y. Kuroda, "Detection of the 14-3-3 protein in the cerebrospinal fluid of Japanese multiple sclerosis patients presenting with severe myelitis," Journal of the Neurological Sciences, vol. 212, no. 1-2, pp. 11-20, 2003.

[188] D. N. Irani and D. A. Kerr, "14-3-3 Protein in the cerebrospinal fluid of patients with acute transverse myelitis," Lancet, vol. 355, no. 9207, p. 901, 2000.

[189] B. N. Hammack, K. Y. C. Fung, S. W. Hunsucker et al., "Proteomic analysis of multiple sclerosis cerebrospinal fluid," Multiple Sclerosis, vol. 10, no. 3, pp. 245-260, 2004.

[190] D. Dumont, J. P. Noben, J. Raus, P. Stinissen, and J. Robben, "Proteomic analysis of cerebrospinal fluid from multiple sclerosis patients," Proteomics, vol. 4, no. 7, pp. 2117-2124, 2004.

[191] A. J. Elderfield, J. Newcombe, C. Bolton, and R. J. Flower, "Lipocortins (annexins) 1, 2, 4 and 5 are increased in the central nervous system in multiple sclerosis," Journal of Neuroimmunology, vol. 39, no. 1-2, pp. 91-100, 1992.

[192] M. J. Craner, A. C. Lo, J. A. Black et al., "Annexin II/PII is upregulated in Purkinje cells in EAE and MS," NeuroReport, vol. 14, no. 4, pp. 555-558, 2003.
[193] J. P. Noben, D. Dumont, N. Kwasnikowska et al., "Lumbar cerebrospinal fluid proteome in multiple sclerosis: characterization by ultrafiltration, liquid chromatography, and mass spectrometry," Journal of Proteome Research, vol. 5, no. 7, pp. 1647-1657, 2006.

[194] S. Elkabes and H. Li, "Proteomic strategies in multiple sclerosis and its animal models," Proteomics, vol. 1, no. 11, pp. 1393-1405, 2007.

[195] N. Mattsson, U. Rüetschi, V. N. Podust et al., "Cerebrospinal fluid concentrations of peptides derived from chromogranin B and secretogranin II are decreased in multiple sclerosis," Journal of Neurochemistry, vol. 103, no. 5, pp. 1932-1939, 2007.

[196] E. K. Mathey, T. Derfuss, M. K. Storch et al., "Neurofascin as a novel target for autoantibody-mediated axonal injury," Journal of Experimental Medicine, vol. 204, no. 10, pp. 23632372, 2007.

[197] R. A. Linker, P. Brechlin, S. Jesse et al., "Proteome profiling in murine models of multiple sclerosis: identification of stage specific markers and culprits for tissue damage," PLoS ONE, vol. 4 , no. 10, article e7624, 2009.

[198] H. Tumani, C. Teunissen, S. Süssmuth, M. Otto, A. C. Ludolph, and J. Brettschneider, "Cerebrospinal fluid biomarkers of neurodegeneration in chronic neurological diseases," Expert Review of Molecular Diagnostics, vol. 8, no. 4, pp. 479-494, 2008.

[199] H. Tumani, H.-P. Hartung, B. Hemmer et al., "Cerebrospinal fluid biomarkers in multiple sclerosis," Neurobiology of Disease, vol. 35, no. 2, pp. 117-127, 2009.

[200] A. Petzold, A. Altintas, L. Andreoni et al., "Neurofilament ELISA validation," Journal of Immunological Methods, vol. 352, no. 1-2, pp. 23-31, 2010.

[201] C. E. Teunissen, A. Petzold, J. L. Bennett et al., "A consensus protocol for the standardization of cerebrospinal fluid collection and biobanking," Neurology, vol. 73, no. 22, pp. 19141922, 2009. 


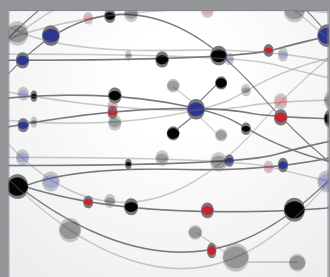

The Scientific World Journal
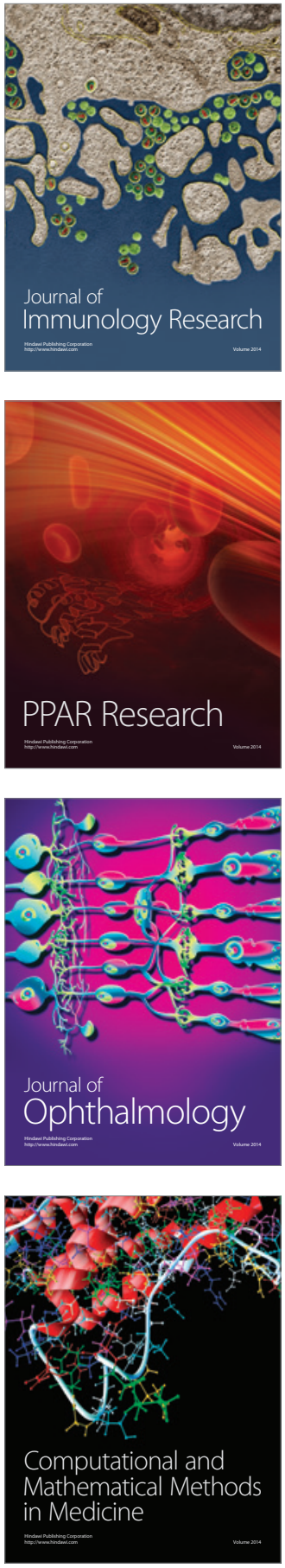

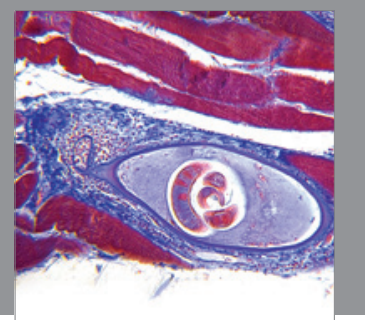

Gastroenterology

Research and Practice
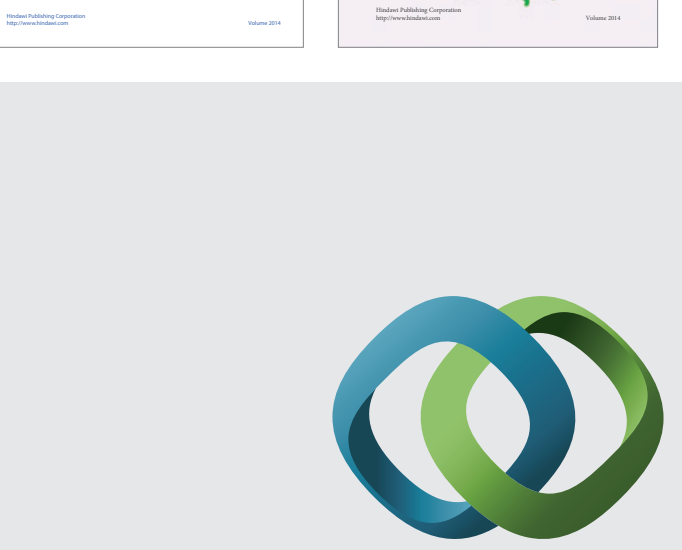

\section{Hindawi}

Submit your manuscripts at

http://www.hindawi.com
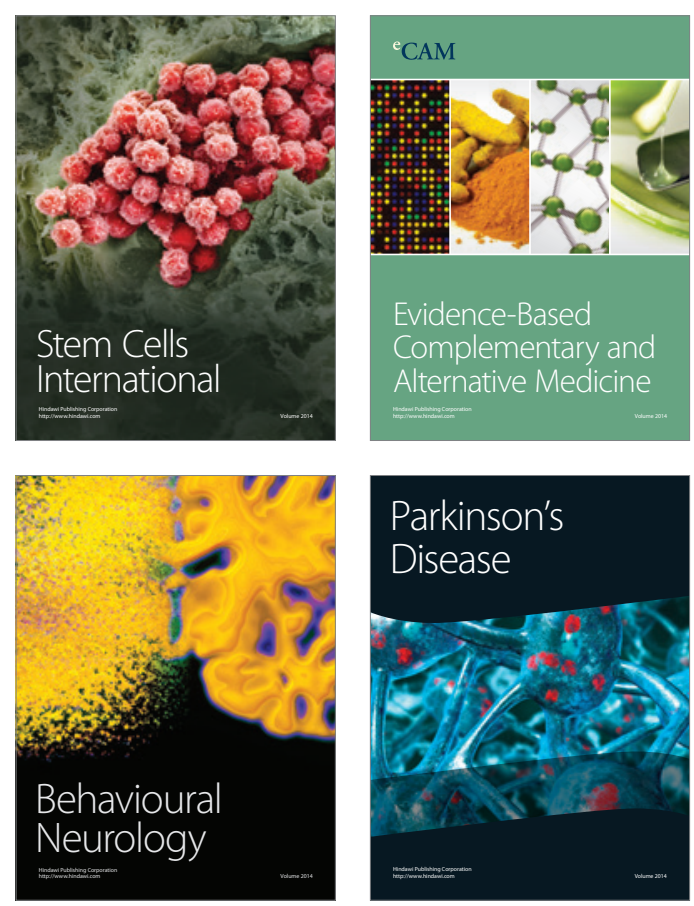

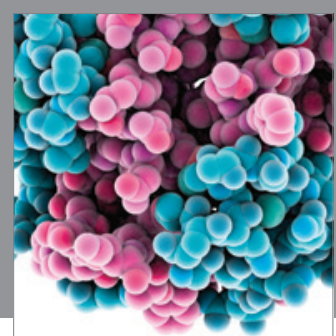

Journal of
Diabetes Research

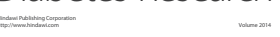

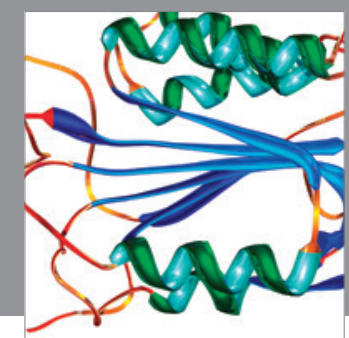

Disease Markers
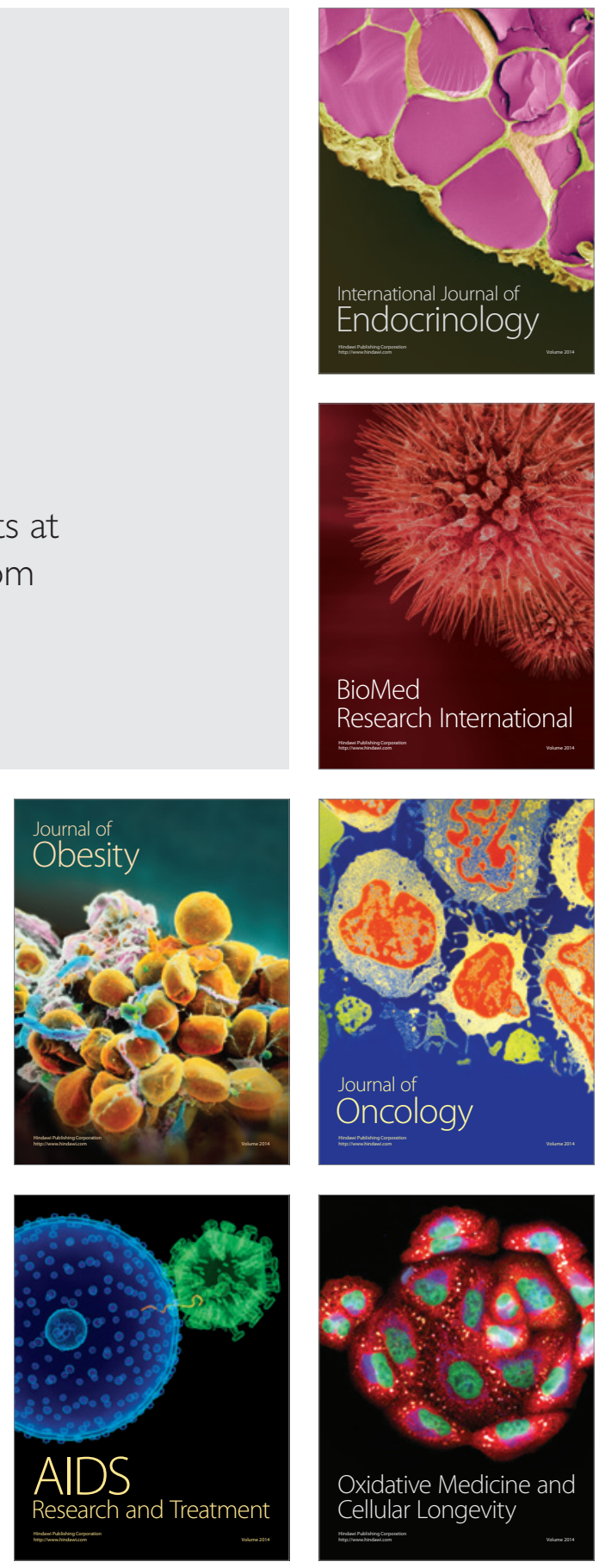